\title{
Novel and Known Gene-Smoking Interactions With cIMT Identified as Potential Drivers for Atherosclerosis Risk in West-African Populations of the AWI-Gen Study
}

\author{
Palwende Romuald Boua 1,2,3*, Jean-Tristan Brandenburg ${ }^{2}$, Ananyo Choudhury ${ }^{2}$, \\ Scott Hazelhurst ${ }^{2,4}$, Dhriti Sengupta ${ }^{2}$, Godfred Agongo ${ }^{2,3,5}$, Engelbert A. Nonterah ${ }^{5,6}$, \\ Abraham R. Oduro ${ }^{5}$, Halidou Tinto ${ }^{1}$, Christopher G. Mathew ${ }^{2,7}$, Hermann Sorgho ${ }^{1}$ \\ and Michèle Ramsay ${ }^{2,3}$ \\ ${ }^{1}$ Clinical Research Unit of Nanoro, Institut de Recherche en Sciences de la Santé, Nanoro, Burkina Faso, ${ }^{2}$ Faculty of Health \\ Sciences, Sydney Brenner Institute for Molecular Bioscience (SBIMB), University of the Witwatersrand, Johannesburg, \\ South Africa, ${ }^{3}$ Division of Human Genetics, National Health Laboratory Service and School of Pathology, Faculty of Health \\ Sciences, University of the Witwatersrand, Johannesburg, South Africa, ${ }^{4}$ School of Electrical and Information Engineering, \\ University of the Witwatersrand, Johannesburg, South Africa, ${ }^{5}$ Navrongo Health Research Centre, Ghana Health Service, \\ Navrongo, Ghana, ${ }^{6}$ Julius Center for Health Sciences and Primary Care, University Medical Center Utrecht, Utrecht \\ University, Utrecht, Netherlands, ${ }^{7}$ Department of Medical and Molecular Genetics, Faculty of Life Sciences and Medicine, \\ King's College London, London, United Kingdom
}

\section{OPEN ACCESS}

Edited by:

Mayowa Ojo Owolabi,

University of Ibadan, Nigeria

Reviewed by:

Liyong Wang,

University of Miami, United States

Linda Polfus,

University of Southern California,

United States

*Correspondence:

Palwende Romuald Boua

romyboua@gmail.com

Specialty section:

This article was submitted to

Evolutionary and Population Genetics,

a section of the journal

Frontiers in Genetics

Received: 27 February 2019

Accepted: 10 December 2019

Published: 07 February 2020

Citation:

Boua PR, Brandenburg J-T,

Choudhury A, Hazelhurst $S$, Sengupta $D$, Agongo G, Nonterah EA,

Oduro AR, Tinto $H$, Mathew CG,

Sorgho H and Ramsay M (2020) Novel

and Known Gene-Smoking

Interactions With cIMT Identified as

Potential Drivers for Atherosclerosis

Risk in West-African Populations of the

AWI-Gen Study.

Front. Genet. 10:1354.

doi: 10.3389/fgene.2019.01354
Introduction: Atherosclerosis is a key contributor to the burden of cardiovascular diseases (CVDs) and many epidemiological studies have reported on the effect of smoking on carotid intima-media thickness (CIMT) and its subsequent effect on CVD risk. Gene-environment interaction studies have contributed towards understanding some of the missing heritability of genome-wide association studies. Gene-smoking interactions on CIMT have been studied in non-African populations (European, LatinoAmerican, and African American) but no comparable African research has been reported. Our aim was to investigate smoking-SNP interactions on CIMT in two West African populations by genome-wide analysis.

Materials and methods: Only male participants from Burkina Faso (Nanoro $=993)$ and Ghana (Navrongo $=783$ ) were included, as smoking was extremely rare among women. Phenotype and genotype data underwent stringent QC and genotype imputation was performed using the Sanger African Imputation Panel. Smoking prevalence among men was $13.3 \%$ in Nanoro and $42.5 \%$ in Navrongo. We analyzed gene-smoking interactions with PLINK after adjusting for covariates: age and 6 PCs (Model 1); age, BMI, blood pressure, fasting glucose, cholesterol levels, MVPA, and 6 PCs (Model 2). All analyses were performed at site level and for the combined data set.

Results: In Nanoro, we identified new gene-smoking interaction variants for cIMT within the previously described RCBTB1 region (rs112017404, rs144170770, and rs4941649) (Model 1: $p=1.35 E-07 ;$ Model 2: $p=3.08 E-08$ ). In the combined sample, two novel 
intergenic interacting variants were identified, rs1192824 in the regulatory region of TBC1D8 $(p=5.90 \mathrm{E}-09)$ and $r 577461169$ ( $p=4.48 \mathrm{E}-06)$ located in an upstream region of open chromatin. In silico functional analysis suggests the involvement of genes implicated in biological processes related to cell or biological adhesion and regulatory processes in gene-smoking interactions with cIMT (as evidenced by chromatin interactions and eQTLs).

Discussion: This is the first gene-smoking interaction study for CIMT, as a risk factor for atherosclerosis, in sub-Saharan African populations. In addition to replicating previously known signals for RCBTB1, we identified two novel genomic regions (TBC1D8, near BCHE) involved in this gene-environment interaction.

Keywords: GWIS, atherosclerosis, smoking, carotid intima-media thickness, gene-environment interactions

\section{INTRODUCTION}

During the last two decades, the burden of cardiovascular diseases (CVDs) has increased considerably, and low- and middle-income countries are now experiencing about $80 \%$ of the worldwide burden. Sub-Saharan Africa (SSA) is undergoing a health and demographic transition that has shifted the major causes of death from communicable and nutritional diseases to noncommunicable diseases (NCDs). The mean age of death attributable to CVDs in SSA in 2010 was 64.9 years (95\% CI, 64.4-65.4) compared with 67.6-81.2 years for the rest of the world (Roth et al., 2015), making it one of the youngest affected populations globally. Populations of African descent have been under-represented in genomic studies, representing only about $3 \%$ of the participants worldwide used for genome-wide association studies up to 2016 (Popejoy and Fullerton, 2016). This is a gap that needs to be filled, considering that Africa is the continent with the highest genetic diversity owing to its deep evolutionary roots, and African genomes generally have lower linkage disequilibrium (LD). A previous study reported that African populations were more diverse and had significantly more genes and pathways involved in extreme allele frequency differences (EAFD) (Sulovari et al., 2017). The African genome is therefore highly relevant for the discovery of new genetic associations and a better understanding of human disease mechanisms (Tekola-Ayele and Rotimi, 2015; Choudhury et al., 2018; Martin et al., 2018).

Genetic understanding of complex traits has developed immensely over the past decade but remains hampered by the fact that genetic variants still explain only a fraction of the heritability of a trait, often referred to as the missing heritability. A contributor to this phenotypic variance is gene-environment interaction (GxE) (Duncan et al., 2014). GxE can be defined broadly as the interplay between the product of a genetic variant and an environmental factor as they affect a specific trait. $\mathrm{GxE}$ therefore refers to modification, by an environmental factor, of the effect of a genetic variant on a phenotypic trait. The phenotypic flexibility resulting from adjustments due to $\mathrm{GxE}$ could determine or modulate health or disease by modulating the adverse effects of a risk allele, or exacerbating the genotypephenotype relationship to increase risk. Environmental stimuli, acting over hundreds of generations, have promoted adaptation that is reflected in allele frequency shifts observed in current populations for traits and disease risk.
Identifying GxE represents a cornerstone in "Precision Public Health" that will allow individuals to adjust exposure to a particular environmental factor involved in GxE interactions for the benefit of reducing disease risk in accordance with specific genotypes. However, if $\mathrm{GxE}$ testing represents an opportunity, challenges remain in interaction studies. The ability to detect interactions can be dependent on scale, SNP-based analyses can lack power, exposure measurements can be inconsistent and imperfect, and optimal software for efficient $\mathrm{GxE}$ analysis is lacking. Fortunately, recent advances in methodology development have boosted $\mathrm{GxE}$ interaction analysis and more studies are being published.

Smoking is an important risk factor for coronary heart disease (CHD) and CVD (Schroeder, 2013). Despite improved understanding, the pathophysiological mechanisms underpinning the association between smoking and CVD have yet to be elucidated fully. Nonetheless smoking is known to have an effect on endothelial cells, inflammatory states, platelet activation, procoagulant factors, and antifibrinolytic factors (Barua and Ambrose, 2013). Several studies have reported the effect of smoking on subclinical atherosclerosis (Liang et al., 2009; Yang et al., 2015; Hansen et al., 2016; Kianoush et al., 2017). Atherosclerosis is a complex, progressive disorder affecting large and medium-sized arteries. The disease has a silent progression, often with no clinical evidence until the occurrence of a vascular event.

Gene-smoking interactions for atherosclerosis have been reported. In the Bogalusa Heart Study, a variant located in the region of EDNRA was found to be associated with the status of the left cIMT (Li et al., 2015), and in the Northern Manhattan Study (NOMAS), RCBTB1 was reported as a modifier of the smoking effect on CIMT, and MXD1-JPH1 for carotid plaque burden in the presence of smoking (Wang et al., 2014; Della-Morte et al., 2014). Genes involved in inflammatory pathways mediated by the NF-kB axis (TBC1D4 and ADAMTS9) have been identified as displaying gene-smoking interactions (Polfus et al., 2013). In 2017, a casecontrol study on CHD identified variants in ADAMTS7 associated with a loss of cardio-protective effects resulting from gene-smoking interactions (Saleheen et al., 2017).

The Africa Wits-INDEPTH partnership for Genomic Studies (AWI-Gen), a Collaborative Centre of the Human Heredity and Health in Africa (H3Africa) Consortium, was developed to investigate the genomic and environmental risk factors for 
cardio-metabolic diseases in Africans. In this paper, we report on a genome-wide analysis of gene-environment interactions to explore the role of smoking on cIMT (a measure of atherosclerosis) in male participants from Nanoro (Burkina Faso) and Navrongo (Ghana) in West-Africa, as part of the AWI-Gen study.

\section{METHODS}

\section{Study Population}

AWI-Gen is a cross-sectional study of adults (40 to 60 years of age) and in this study we used a subset of participants from the AWI-Gen study (Derra et al., 2012; Oduro et al., 2012; Ramsay et al., 2016; Ali et al., 2018), including male participants from the two study sites in West Africa. The participants for this study included 1,776 West African men from two rural settings, Nanoro (Burkina Faso) and Navrongo (Ghana). Only men were included in this study as smoking rates in women are very low in these communities. Participants completed a questionnaire with questions on demography, health history and behaviour. The reason for only performing the analysis on the two West African study sites, and not the other AWI-Gen study sites, is that they were comparable in terms of environmental exposures, genetic background, and prevalence of HIV infection (Derra et al., 2012; Oduro et al., 2012).

\section{cIMT Measurement}

cIMT was measured using Dual B-mode ultrasound images of the carotid tree showing a typical double line for the arterial wall. cIMT is best visible in the measurement segment of the distal common carotid artery with lowest measurement variability. The measurement is most reliable over a one centimeter segment and was performed by semi-automatic reading methods, which minimise reading errors. The far wall of both the left and right common carotid artery was imaged using a linear-array 12L-RS transducer with a GE Healthcare B-mode LOGIQe ultrasound machine (GE, Healthcare, CT, USA). The participant was in a supine position for the measurements, head turned towards the left at a 45-degree angle to measure the right carotid. Operators used anatomical landmarks to identify the common carotid artery (CCA) on a longitudinal plane and the image was frozen. The operator then identified a continuous onecentimeter segment $(10 \mathrm{~mm})$ of the CCA far wall and placed a cursor between two points (10 $\mathrm{mm}$ apart) on this identified segment with the proximal starting point $1 \mathrm{~cm}$ from the bulb of the CCA. The inbuilt software then automatically detected the intima-lumen and the media-adventitia interfaces and calculated the minimum, maximum and mean common cIMT in $\mathrm{mm}$ and to two decimal places. To measure the left carotid, the participant's head was turned to the opposite side, and the process was repeated. The cIMT values were QCed according to the Mannheim Consensus defining the use of cIMT in population-based studies. We generated the mean cIMT as the average of the mean common right and left cIMT and used this variable for all analyses.

\section{Smoking Status and Other Variables}

Smokers (current) and nonsmokers (never and former) were classified based on self-reporting. A dichotomous categorization of smoking status was chosen over a quantitative measure (e.g., pack-years) owing to the inherent high dimensionality of GWAS analysis (13.98 million SNPs with two-fold main effects and interaction variables per SNP). Additionally, previous studies reported the reversal of the effect of smoking after several years of cessation. Smoking intensity was assessed using pack/years calculated by multiplying the number of packs of cigarettes smoked per day by the number of years the person has smoked. The number of cigarettes or times a tobacco product were consumed was recorded at intervals of days (everyday, 5-6 days, 1-4 days, 1-3 days/month, less than once a month).

Other variables (height $(\mathrm{m})$, weight $(\mathrm{kg}), \mathrm{BMI}\left(\mathrm{kg} / \mathrm{m}^{2}\right)$, blood pressure, fasting glucose, total cholesterol and physical activity) were recorded as previously described (Ali et al., 2018).

\section{Association and Follow-Up Analysis Genotype Data and Imputation}

The H3Africa genotyping array ${ }^{1}$, designed as an Africancommon-variant-enriched GWAS array (Illumina) with $\sim 2.3$ million SNPs, was used to genotype genomic DNA using the Illumina FastTrack Sequencing Service ${ }^{2}$. The following preimputation QC steps were applied to the entire AWI-Gen genotype data set. Individuals with a missing SNP calling rate greater than 0.05 were removed. SNPs with a genotype missingness greater than 0.05, MAF less than 0.01, and HardyWeinberg equilibrium (HWE) P-value less than 0.0001 were removed. Nonautosomal and mitochondrial SNPs, and ambiguous SNPs that did not match the GRCh37 references alleles or strands were removed. Imputation was performed on the cleaned data set (with 1,729,661 SNPs and 10,903 individuals from the AWI-Gen study) using the Sanger Imputation Server and the African Genome Resources as reference panel. We selected EAGLE2 (Loh et al., 2016) for prephasing and the default PBWT algorithm was used for imputation. After imputation, poorly imputed SNPs with info scores less than 0.6, MAF less 0.01, and HWE P-value less than 0.00001 were excluded. The final QC-ed imputed data had 13.98 M SNPs, and data from male participants from the Nanoro and Navrongo study sites were extracted for analysis.

\section{Data Analysis}

Descriptive statistics were used to summarise the population characteristics. Continuous variables were reported in median and interquartile ranges and categorical variables were reported in percentages. All the data were analyzed per site before reporting for the combined group. We examined group differences using the Mann-Whitney test for continuous variables and Pearson Chi-square test for categorical variables.

\footnotetext{
${ }^{1}$ https://www.h3abionet.org/h3africa-chip

${ }^{2}$ https://www.illumina.com/services/sequencing-services.html
} 
Analyses were performed using mean cIMT and SNPs with a MAF of 0.05 or above.

\section{Gene-Environment Interaction (GxE) Analysis}

Linear regression of mean cIMT was performed with covariates using $\mathrm{R}^{3}$. Residuals were extracted from the linear regression analyses and used for the GWAS analysis. Model 1 used the following covariates: age and six principal components (PCs) computed on genetics data (to account for genetic structure). To check the consistency of our association, Model 2 included further adjustment [Model $1+$ BMI + systolic blood pressure + diastolic blood pressure + fasting glucose + total cholesterol + physical activity (moderate to vigorous physical activity in minutes per week (MVPA)] to analyze SNPs with pvalues < 1 E-06 in Model 1.

GxE testing was performed using the PLINK “-gxe” option (Purcell et al., 2007; Chang et al., 2015) on the "awigen" branch of the automated workflow ${ }^{4}$ (Baichoo et al., 2018). We screened the output for a genome-wide significance threshold (p-values $<$ 5 E-08).

To assess genomic inflation, the observed distribution of $-\log 10(P)$ values was compared to that expected in the absence of association (lambda) and illustrated in QQ plots. We used a cross-replication approach between the two sites, suggestive signals ( $\mathrm{p}$-values $<1 \mathrm{E}-04)$ in one site were checked in the other site and vice versa.

Power calculations were performed with Quanto ${ }^{5}$ (Version 1.2.4). The study was powered at $80 \%$ to identify SNPs with MAF $\geq 0.05$ and interaction effect size (OR) of $>4$, given our sample size and smoking prevalence in Nanoro. The power would be higher for Navrongo and the combined data set because of the increased number of smokers.

\section{Functional Analysis of Associated Variants}

The FUMA online platform ${ }^{6}$ (Watanabe et al., 2017) was used to annotate, prioritize, visualize, and interpret GWAS results. From GWAS summary statistics as an input, it provided extensive functional annotation for all SNPs in genomic areas identified by lead SNPs. From the list of gene IDs (as identified by SNP2GENE option in FUMA) FUMA annotated genes in biological context (Watanabe et al., 2017). We selected all candidate SNPs in the associated genomic region having $\mathrm{r}^{2} \geq 0.6$ with one of the independently significant SNPs, with a suggestive P-value $(\mathrm{P}<1 \mathrm{E}-05)$ and $\mathrm{MAF} \geq 0.05$ for annotation. Predicted functional consequences for these SNPs were obtained by matching the SNP's chromosome base-pair position, and reference and alternate alleles, to databases containing known functional annotations, including ANNOVAR (Wang et al., 2010), combined annotation-dependent depletion (CADD) scores (Kircher et al., 2014), and RegulomeDB (RDB) (Boyle et al., 2012) scores.

\footnotetext{
${ }^{3}$ https://www.R-project.org/

${ }^{4}$ http://github.com/h3abionet/h3agwas/

${ }^{5}$ http://biostats.usc.edu/Quanto.html

${ }^{6}$ http://fuma.ctglab.nl/
}

\section{Functional Annotation of Mapped Genes}

Genes implicated by mapping of significant GWAS SNPs were further investigated using the GENE2FUNC procedure in FUMA (Watanabe et al., 2017), which provides hypergeometric tests of enrichment of the list of mapped genes in 53 GTEx tissue-specific gene expression sets (The GTExArd Consortium et al., 2015; GTex Consortium et al., 2017), 7,246 MSigDB gene sets ${ }^{7}$, and chromatin states (Ernst and Kellis, 2013; Consortium Roadmap Epigenomics et al., 2015).

\section{GWAS Catalog Lookup}

The GWAS Catalog database was downloaded from the website ${ }^{8}$ (Accessed on 12 Jul 2018) and a subset the data set generated using the following key words relevant to our study: genomewide interaction, gene-environment interactions, atherosclerosis, coronary artery diseases, carotid atherosclerosis, cIMT, coronary artery calcification, abdominal artery aneurism. Since our data set was in build 37, we performed a lift-over prior to comparison. In order to assess whether our study was replicating previous findings, we searched for the same marker or any markers within $100 \mathrm{~kb}$ of all suggestive index SNPs ( $\mathrm{p}$-value $\leq 1 \mathrm{E}-04$ ) found in this study and further filtered the list using key words pertaining to coronary artery diseases and gene-environment interactions.

\section{Ethics and Consent}

This study received the approval of the Human Research Ethics Committee (Medical), University of the Witwatersrand, South Africa (M121029), the approval of the Centre Muraz Institutional Ethics Committee, Burkina Faso (015-2014/CE$\mathrm{CM}$ ) and the approval of the National Ethics Committee For Health Research, Burkina Faso (2014-08-096), the Ghana Health Service Ethics Review Committee (ID No: GHS-ERC:05/05/ 2015), and the Navrongo Institutional Review Board (ID No: NHRCIRB178). All the participants signed an Informed Consent Form before any study procedure was performed.

\section{RESULTS}

\section{Characteristics of Participants}

The participant characteristics are presented for Nanoro $(\mathrm{n}=$ 993), Navrongo ( $n=783)$, and for the combined data $(n=1776)$ in Table 1. Only males were included. The prevalence of current smokers was $13.3 \%, 42.5 \%$ and $26.2 \%$, respectively for Nanoro, Navrongo, and the combined data set. Smokers were younger than nonsmokers in Nanoro. Interestingly, although the prevalence of current smokers was lower, the smoking intensity was much higher (in packs/year) in Nanoro, 6.6 (3.711.6) vs 1.7 (0-4.2) in Navrongo. Moreover, although there were no differences in mean cIMT values between smokers and nonsmokers, significant differences were observed for the following risk factors, BMI, systolic, and diastolic blood pressure, for both sites and overall. Total cholesterol and low density lipid cholesterol (LDL-C) were lower in smokers

\footnotetext{
${ }^{7}$ http://software.broadinstitute.org/gsea/msigdb

${ }^{8}$ https://www.ebi.ac.uk/gwas/
} 
TABLE 1 | Descriptive characteristics for participants from Nanoro (Burkina Faso) and Navrongo (Ghana) and the combined sample.

\begin{tabular}{|c|c|c|c|c|c|c|c|c|c|}
\hline & \multicolumn{3}{|c|}{ Nanoro } & \multicolumn{3}{|c|}{ Navrongo } & \multicolumn{3}{|c|}{ All } \\
\hline & $\begin{array}{c}\text { Nonsmokers } \\
(861)\end{array}$ & Smokers (132) & $\begin{array}{c}\text { p- } \\
\text { values } \phi\end{array}$ & $\begin{array}{c}\text { Nonsmokers } \\
(450)\end{array}$ & Smokers (333) & $\begin{array}{c}\mathrm{p}- \\
\text { values } \phi\end{array}$ & $\begin{array}{c}\text { Nonsmokers } \\
\text { (1311) }\end{array}$ & Smokers (465) & $\begin{array}{c}\mathrm{p}- \\
\text { values } \phi\end{array}$ \\
\hline Age (year) & $50(45-55)$ & $48(43-52)$ & 0.0024 & $50(45-56)$ & $51(46-55)$ & 0.5053 & $50(45-55)$ & $50(45-55)$ & 0.6104 \\
\hline BMI $\left(\mathrm{kg} / \mathrm{m}^{2}\right)$ & $\begin{array}{c}21.31(19.47- \\
23.61)\end{array}$ & $\begin{array}{c}19.50(17.99- \\
21.54)\end{array}$ & $<0.001$ & $\begin{array}{c}20.99(19.42- \\
22.95)\end{array}$ & $\begin{array}{c}20.03(18.58- \\
21.44)\end{array}$ & $<0.001$ & $\begin{array}{c}21.22(19.46- \\
23.37)\end{array}$ & $\begin{array}{c}19.90(18.38- \\
21.45)\end{array}$ & $<0.001$ \\
\hline Systolic BP (mmHg) & $118(109-132)$ & $113(101-124)$ & $<0.001$ & $123(112-136)$ & $119(108-133)$ & 0.0033 & $120(110-133)$ & $117(107-131)$ & 0.0016 \\
\hline Diastolic BP (mmHg) & 76 (69-83) & $72(64-81)$ & 0.0012 & 76 (68-85) & 74 (66-83) & 0.0233 & 76 (69-84) & 74 (65-82) & $<0.001$ \\
\hline $\begin{array}{l}\text { Fasting Glucose } \\
(\mathrm{mmol} / \mathrm{l})\end{array}$ & $4.90(4.46-5.35)$ & $4.94(4.52-5.42)$ & 0.5672 & $4.49(4.05-5.00)$ & $4.29(3.94-4.73)$ & $<0.001$ & $4.77(4.30-5.24)$ & $4.47(4.06-4.96)$ & $<0.001$ \\
\hline $\begin{array}{l}\text { Total cholesterol } \\
(\mathrm{mmol} / \mathrm{l})\end{array}$ & 3.59 (2.96-4.26) & $3.3(2.88-3.84)$ & 0.0063 & $3.10(2.57-3.66)$ & $3.18(2.61-3.67)$ & 0.4888 & 3.37 (2.78-4.10) & $3.21(2.67-3.70)$ & $<0.001$ \\
\hline $\begin{array}{l}\text { Triglycerides } \\
(\mathrm{mmol} / \mathrm{l})\end{array}$ & $0.70(0.53-0.97)$ & $0.70(0.55-0.94)$ & 0.7984 & $0.55(0.42-0.73)$ & $0.57(0.43-0.73)$ & 0.6104 & $0.64(0.48-0.89)$ & $0.60(0.45-0.77)$ & $<0.001$ \\
\hline LDL-C (mmol/l) & $1.98(1.51-2.55)$ & $1.82(1.44-2.14)$ & 0.0031 & 1.70 (1.22-2.19) & 1.67 (1.28-2.06) & 0.6141 & 1.88 (1.39-2.44) & $1.72(1.31-2.08)$ & $<0.001$ \\
\hline HDL-C (mmol/l) & $1.12(0.94-1.36)$ & $1.13(0.88-1.41)$ & 0.8254 & 1.12 (0.89-1.34) & $1.16(0.94-1.45)$ & 0.0352 & $1.12(0.92-1.36)$ & $1.16(0.92-1.43)$ & 0.1209 \\
\hline MVPA (min/week) & $\begin{array}{c}1,485(80- \\
3,055)\end{array}$ & $\begin{array}{c}2,520(420- \\
3,155)\end{array}$ & 0.0185 & $\begin{array}{c}2,408(1,035- \\
3,060)\end{array}$ & $\begin{array}{c}2,475(1,080- \\
3,120)\end{array}$ & 0.7610 & $\begin{array}{c}2,220(250- \\
3,060)\end{array}$ & $\begin{array}{c}2,490(720- \\
3,120)\end{array}$ & $<0.001$ \\
\hline $\begin{array}{l}\text { Cigarette (Pack/ } \\
\text { Year) }^{\mathrm{Y}}\end{array}$ & - & $6.6(3.7-11.6)$ & - & - & $1.7(0-4.2)$ & - & - & $2.8(0-6)$ & - \\
\hline Mean clMT (mm) & $\begin{array}{c}0.673(0.598- \\
0.758)\end{array}$ & $\begin{array}{c}0.656(0.585- \\
0.736)\end{array}$ & 0.0952 & $\begin{array}{c}0.678(0.610- \\
0.768)\end{array}$ & $\begin{array}{c}0.680(0.607- \\
0.753)\end{array}$ & 0.7332 & $\begin{array}{c}0.675(0.603- \\
0.760)\end{array}$ & $\begin{array}{c}0.675(0.598- \\
0.750)\end{array}$ & 0.4297 \\
\hline
\end{tabular}

$\oplus$ Mann-Whitney rank-sum test, $p$-values at $p<0.05$ are shown in bold.

${ }^{r}$ Number of pack-years $=($ number of cigarettes smoked per day/20) $\times$ number of years smoked.

BMI, body mass index; BP, blood pressure; MVPA, moderate to vigorous physical activity.

compared to nonsmokers in Nanoro and the combined sample, whereas fasting glucose was lower for smokers in Navrongo and the combined sample. In spite of the geographic and genetic proximity of the two groups, the differences in the prevalence and smoking intensity, as well as that of other risk factors, suggest that the GxE interaction mechanism might not be the same in the two study centres.

\section{Gene-Smoking Interactions}

The association results of SNPs (MAF $\leq 0.05)$ are illustrated by Manhattan plots for each site and the combined data set in Figures 1A-C. Genomic inflation factors (GIFs) (lambda) were $0.994,0.993$, and 1.007 , respectively for Nanoro $(7,828,913$ SNPs), Navrongo (7,842,446 SNPs), and the combined sample (7,839,440 SNPs) (Figures 1D-F).

The strongest signal in the Nanoro sample was found for the GxE where the C allele of rs7649061 (allele frequency (AF) = 0.25 , p-value $=7.37 \mathrm{E}-08$ ) was associated with a decrease of mean-cIMT in the presence of smoking (Table $\mathbf{2 A}$, Supplementary Table $\mathbf{1}$ ). This variant is located in an intergenic region between $B C H E$ (butyrylcholinesterase) and $Z B B X$ (zinc finger B-box domain containing). Four other regions had signals with $\mathrm{p}<5 \mathrm{E}-07$ in the analysis for Nanoro: rs7095209 ( $\mathrm{p}$-value $=1.23 \mathrm{E}-07)$, an intergenic SNP close to the SORCS3 gene (sortilin related VPS10 domain containing receptor 3$)$, the $\mathrm{G}$ allele of which $(\mathrm{AF}=0.42)$ was associated with a decrease of mean-cIMT in the presence of smoking (Supplementary Figures 1 and 2); three chromosome 13 variants in high LD (rs112017404, rs144170770 and rs4941649), with the lowest $\mathrm{p}$-value at $1.35 \mathrm{E}-07(\mathrm{AF}=0.08)$, associated with an increase of mean-cIMT in smokers, and located between RCBTB1 (Regulator of chromosome condensation (RCC1) and BTB (POZ) domain containing protein 1) and ARL11 (ADP-ribosylation factor-like 11) (Figure 2A); rs13268575 ( $\mathrm{p}=2.77 \mathrm{E}-07$ ) in the CNBD1 (cyclic nucleotide binding domain containing 1 ) region which was associated with an increase of mean-cIMT in smokers for the A allele $(\mathrm{AF}=0.23)$; and a missense variant, $r$ rs17844302 ( $\mathrm{p}$ value $=4.07 \mathrm{E}-07$ ), in PCDHA6 (protocadherin alpha 6), found to be associated with an increase of mean-cIMT in smokers.

The associations for the analysis of the Navrongo data were less significant with none reaching $\mathrm{p}<1 \mathrm{E}-07$ (Table 2B, Supplementary Table 1). The strongest association signal was for rs4869800 (p-value $=1.92 \mathrm{E}-06, \mathrm{AF}=0.92$ ), an intergenic variant between RGS17 (regulator of G-protein signaling 17) and OPRM1 (opioid receptor, mu 1). Other suggestive signals included genes from the olfactory receptor (OR) family. While there could indeed be true signals in the OR gene family, given the high false positive variant discovery rate in this gene family (Chen et al., 2017), it is difficult to assess the robustness of this association using imputed data sets, therefore we excluded these variants from the downstream analyses.

In the combined sample, one SNP (rs1192824) reached the genome-wide significance level (Table 2C, Supplementary Table 1). The C allele of rs1192824 (AF $=0.69)$, located in the intergenic region between TBC1D8 (TBC1 domain family, member 8) and CNOT11 (CCR4-NOT Transcription Complex Subunit 11), showed a SNP-smoking interaction associated with a lower cIMT in smokers compared to the T carriers $(\mathrm{p}=5.90 \mathrm{E}$ 09) (Figure 2B). Another variant in the promoter flanking region of TBC1D8, rs77461169, 5648 bp away from rs1192824, showed a suggestive interaction $(\mathrm{p}=4.48 \mathrm{E}-06)$, and was located in an open chromatin region. The two variants were not in LD (Figure 2C). The distribution of mean cIMT for the three rs1192824 


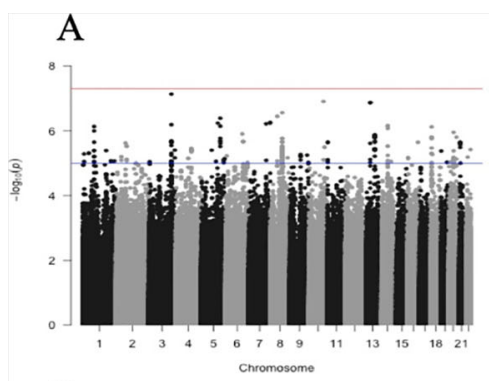

$\mathrm{D}$

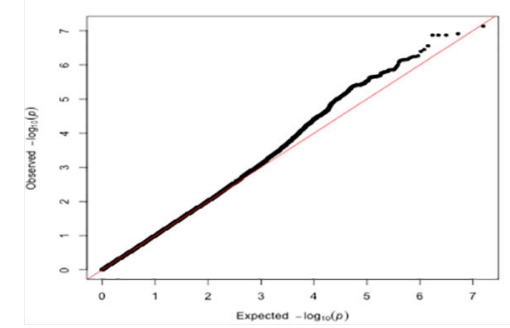

B

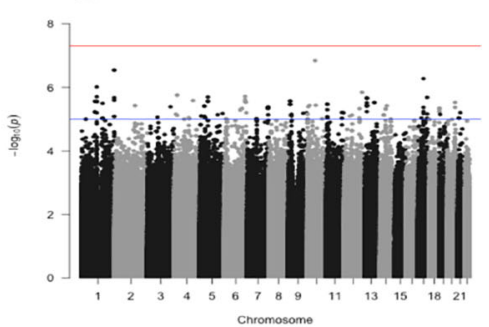

$\mathrm{E}$

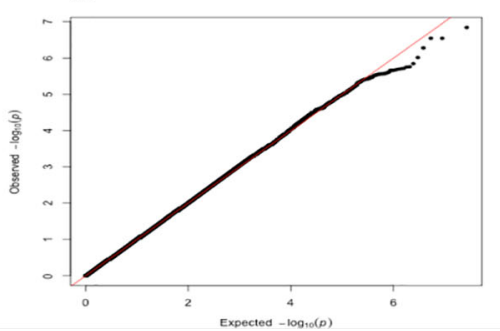

$\mathrm{C}$

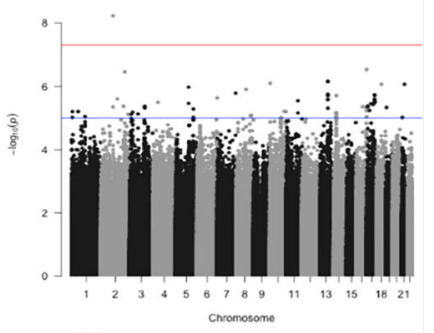

$\mathrm{F}$

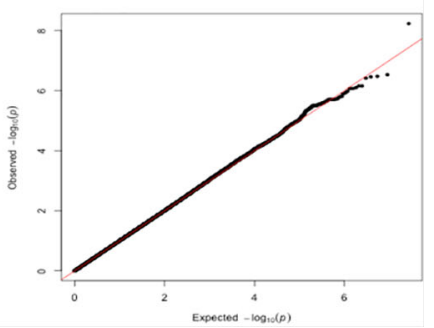

FIGURE 1 | Manhattan plots showing the -log10-transformed two-tailed P-value of each SNP from the GWAS gene-smoking interaction for cIMT on the $y$-axis and base-pair positions along the chromosomes on the $x$-axis. The red line indicates Bonferroni-corrected genome-wide significance $(p<5 E-08)$; the blue line indicates the threshold for suggestive association ( $\mathrm{p}<1 \mathrm{E}-04$ ). Manhattan plot for Nanoro, 993 participants, 78289913 SNPs (A). Manhattan plot for Navrongo, 783 participants, 7842446 SNPs (B). Manhattan plot for combined set, 1776 participants, 7839440 SNPs (C). QQ plot for Nanoro, GIF = 0.9944 (D). QQ plot for Navrongo, GIF = 0.9934 (E). QQ plot for combined set, GIF = 1.0079 (F). GIF [genomic inflation factor (lambda)].

genotypes showed no difference in the nonsmokers, but there was a significant decrease of mean-cIMT for homozygote $(\mathrm{C} / \mathrm{C})$ and heterozygote $(\mathrm{C} / \mathrm{T})$ carriers among the smokers, when compared to the T/T genotype (Figure 3). This suggests a recessive mode of action for the risk allele $(\mathrm{T})$. The second strongest signal was observed for rs12444312 ( $\mathrm{p}$-value $=1.27 \mathrm{E}$ 07) located in a noncoding RNA exon of LOC440390. This SNP is a regulatory region variant located in a CTCF binding site. A signal was found with rs11695675 (p-value $=3.48 \mathrm{E}-07)$ near FTCDNL1 (formiminotransferase cyclodeaminase N-terminal like). Near PCSK9, rs1158815 was found suggestive of the GxE interaction for cIMT in the combined sample at $\mathrm{p}$-value $=6.22 \mathrm{E}$ 06 (Supplementary Figures 1 and 2).

When adjustment was applied for additional covariates, Model $1+$ BMI + systolic blood pressure + diastolic blood pressure + fasting glucose + cholesterol + physical activity (MVPA), in Model 2, four variants in 2 loci reached genomewide significance (rs7649061, p $=2.20 \mathrm{E}-08$; rs112017404rs144170770-rs4941649, $\mathrm{p}=3.08 \mathrm{E}-08)$ in Nanoro. In the combined sample, rs1192824 ( $\mathrm{p}=2.70 \mathrm{E}-08)$ remained the single locus below the genome-wide significance threshold (Table 3). The direction of the allelic effect was the same in all cases where significant associations were identified in Nanoro and the combined sample.

\section{Comparison of Association Signals Between Sites}

We found eight SNPs from Nanoro with some evidence for interaction ( $\mathrm{p}$-values $<1 \mathrm{E}-04)$ which showed nominal replication ( $\mathrm{p}$-value $\leq 0.05$ ) in Navrongo, with the strongest being rs77655815 (Nanoro $\mathrm{p}$-value $=4.01 \mathrm{E}-05)$, replicated at $\mathrm{p}$ value of 6.83E-05, and rs79419964 (Nanoro, $\mathrm{p}=8.74 \mathrm{E}-06$; Navrongo, $\mathrm{p}=8.23 \mathrm{E}-04)$, and with $\mathrm{p}=1.06 \mathrm{E}-06(2.66 \mathrm{E}-06$ for Model 2) in the combined analysis. From Navrongo, 19 SNPs ( $\mathrm{p}<1 \mathrm{E}-04)$ were nominally replicated in Nanoro, of which rs12444312 (Nanoro $\mathrm{p}=1.15 \mathrm{E}-03$ ), was found associated at a $\mathrm{p}$ value of $2.95 \mathrm{E}-07$ in the combined sample (Supplementary Table 1). When significant, the direction of the allelic effect was the same in all cases.

\section{GWAS Catalog Lookup for Gene- Environment Interaction}

We replicated previously described gene-environment association loci for smoking interactions with body composition (BMI and waist circumference) (Justice et al., 2017), smoking or alcohol interaction with blood pressure (Taylor et al., 2016; Feitosa et al., 2018; Sung et al., 2018), coronary artery calcified plaque in type 2 diabetes (Divers et al., 2017) and peripheral arterial disease interaction with air pollution (Ward-Caviness et al., 2017) (Supplementary Table 5). No SNPs from these studies showed evidence of transference of the lead SNPs to African populations in our study, but none was specifically for cIMT as the main outcome. Interestingly, in Nanoro we identified 15 SNPs located within 100 $\mathrm{kb}$ of previously reported gene-environment interaction loci. The loci included a gene-alcohol interaction on blood pressure (Feitosa et al., 2018), gene-smoking interaction on waist circumference (Justice et al., 2017), gene-smoking interaction on lung cancer (Park et al., 2015) and gene-smoking interaction on blood pressure (Sung et al., 2018). In Navrongo, 13 SNPs replicated previous loci for gene-smoking interaction on BMI (Justice et al., 
TABLE 2A | Selected risk loci ( $\mathrm{p} \leq 1 \mathrm{E}-\mathrm{-05})$ for SNP-smoking interactions on cIMT in Nanoro.

\begin{tabular}{|c|c|c|c|c|c|c|c|c|c|c|c|c|c|c|}
\hline rsID & $\mathrm{CHR}$ & POS & $A 1^{4}$ & ${ }^{\prime}$ A2 & $\begin{array}{c}\text { BETA } \\
\text { Nonsmokers }\end{array}$ & $\begin{array}{c}\text { SE } \\
\text { Nonsmokers }\end{array}$ & $\begin{array}{l}\text { Allele Freq } \\
\text { Nonsmokers }\end{array}$ & $\begin{array}{c}\text { BETA } \\
\text { Smokers }\end{array}$ & $\begin{array}{c}\text { SE } \\
\text { Smokers }\end{array}$ & $\begin{array}{c}\text { Allele } \\
\text { Freq Smokers }\end{array}$ & $Z_{-} G_{x E^{*}}$ & P_GXE & Funcrefgene & Generefgene \\
\hline rs205482 & 1 & 10813675 & G & $T$ & $-0,016$ & 0,007 & 0,799 & 0,063 & 0,016 & 0,842 & $-4,558$ & $5,16 \mathrm{E}-06$ & intronic & CASZ1 \\
\hline rs11161464 & 1 & 85298111 & G & A & $-0,015$ & 0,008 & 0,86 & 0,073 & 0,016 & 0,877 & $-4,953$ & 7,34E-07 & intronic & LPAR3 \\
\hline rs1057305 & 1 & 175126223 & A & $\mathrm{T}$ & $-0,006$ & 0,006 & 0,25 & 0,063 & 0,014 & 0,261 & $-4,608$ & $4,08 \mathrm{E}-06$ & UTR3 & KIAA0040 \\
\hline rs79936010 & 1 & 210977179 & G & C & $-0,011$ & 0,008 & 0,114 & 0,081 & 0,019 & 0,11 & $-4,451$ & 8,55E-06 & intronic & $\mathrm{KCNH} 1$ \\
\hline rs148751085 & 2 & 38310007 & $\mathrm{~T}$ & G & 0,021 & 0,006 & 0,216 & $-0,055$ & 0,016 & 0,247 & 4,518 & $6,27 \mathrm{E}-06$ & intergenic & CYP1B1,CYP1B1-AS1 \\
\hline rs11126201 & 2 & 69084017 & A & G & $-0,019$ & 0,005 & 0,508 & 0,042 & 0,012 & 0,492 & $-4,716$ & 2,39E-06 & intergenic & ARHGAP25,BMP10 \\
\hline rs6747064 & 2 & 78141022 & $\mathrm{~T}$ & C & $-0,008$ & 0,007 & 0,163 & 0,074 & 0,016 & 0,161 & $-4,673$ & 2,98E-06 & ncRNA_intronic & LOC101927967 \\
\hline rs4684453 & 3 & 4975879 & $\mathrm{~T}$ & A & 0,015 & 0,006 & 0,277 & $-0,052$ & 0,014 & 0,249 & 4,441 & $9,01 \mathrm{E}-06$ & ncRNA_intronic & BHLHE40-AS1 \\
\hline rs7649061 & 3 & 166457671 & A & C & 0,019 & 0,006 & 0,231 & $-0,058$ & 0,013 & 0,255 & 5,381 & 7,37E-08 & intergenic & BCHE,ZBBX \\
\hline rs779272 & 3 & 191506748 & $\mathrm{~T}$ & A & $-0,025$ & 0,01 & 0,125 & 0,074 & 0,019 & 0,085 & $-4,615$ & 3,94E-06 & intergenic & LINCR-0002,FGF12 \\
\hline rs79243722 & 4 & 93634354 & G & A & $-0,005$ & 0,01 & 0,068 & 0,109 & 0,023 & 0,071 & $-4,49$ & $7,08 \mathrm{E}-06$ & intronic & GRID2 \\
\hline rs6819524 & 4 & 116593891 & G & $\mathrm{T}$ & 0,011 & 0,007 & 0,14 & $-0,081$ & 0,018 & 0,156 & 4,642 & $3,44 \mathrm{E}-06$ & intergenic & NDST4,MIR1973 \\
\hline rs73764616 & 5 & 76294836 & $\mathrm{~T}$ & C & 0,016 & 0,011 & 0,068 & $-0,108$ & 0,025 & 0,069 & 4,613 & 3,96E-06 & intergenic & CRHBP,AGGF1 \\
\hline rs79414964 & 5 & 107950880 & $\mathrm{~T}$ & C & $-0,009$ & 0,011 & 0,049 & 0,127 & 0,029 & 0,063 & $-4,446$ & 8,74E-06 & intergenic & FBXL17,LINC01023 \\
\hline rs2407218 & 5 & 121909381 & G & A & $-0,001$ & 0,011 & 0,045 & 0,154 & 0,029 & 0,06 & $-4,998$ & 5,78E-07 & intergenic & MGC32805,LOC101927379 \\
\hline 5:140208927 & 5 & 140208927 & A & C & $-0,008$ & 0,01 & 0,098 & 0,108 & 0,021 & 0,091 & $-5,064$ & 4,07E-07 & exonic & PCDHA6 \\
\hline rs180973 & 5 & 165988671 & A & G & 0,03 & 0,01 & 0,932 & $-0,086$ & 0,024 & 0,926 & 4,463 & 8,08E-06 & intergenic & LOC102546299,CTB-7E3.1 \\
\hline 5:171912171 & 5 & 171912171 & $\mathrm{~T}$ & C & 0,003 & 0,006 & 0,549 & $-0,057$ & 0,012 & 0,586 & 4,489 & $7,15 \mathrm{E}-06$ & intergenic & SH3PXD2B,NEURL1B \\
\hline rs6934349 & 6 & 6899063 & C & G & 0,016 & 0,006 & 0,33 & $-0,047$ & 0,013 & 0,305 & 4,529 & 5,89E-06 & intergenic & LY86,RREB1 \\
\hline rs699402 & 6 & 122588540 & C & $\mathrm{T}$ & $-0,015$ & 0,01 & 0,072 & 0,111 & 0,024 & 0,074 & $-4,847$ & $1,24 \mathrm{E}-06$ & intergenic & GJA1,HSF2 \\
\hline rs59322395 & 6 & 128914510 & G & A & 0,012 & 0,008 & 0,117 & $-0,087$ & 0,019 & 0,116 & 4,74 & $2,14 \mathrm{E}-06$ & intergenic & PTPRK,LAMA2 \\
\hline rs7450411 & 6 & 161010354 & A & $\mathrm{C}$ & $-0,011$ & 0,009 & 0,125 & 0,075 & 0,017 & 0,097 & $-4,428$ & $9,52 \mathrm{E}-06$ & intronic & LPA \\
\hline rs4728159 & 7 & 128856192 & C & $T$ & $-0,018$ & 0,006 & 0,735 & 0,052 & 0,013 & 0,709 & $-4,989$ & 6,07E-07 & intergenic & SMO,AHCYL2 \\
\hline rs6978311 & 7 & 158665920 & A & G & $-0,012$ & 0,009 & 0,064 & 0,122 & 0,025 & 0,093 & $-5,009$ & $5,47 \mathrm{E}-07$ & intronic & WDR60 \\
\hline rs28890775 & 8 & 52207622 & $\mathrm{~T}$ & C & 0,005 & 0,01 & 0,076 & 0,126 & 0,021 & 0,078 & $-5,091$ & 3,56E-07 & intergenic & SNTG1,PXDNL \\
\hline rs13268575 & 8 & 88391237 & C & A & $-0,005$ & 0,006 & 0,216 & 0,078 & 0,015 & 0,229 & $-5,139$ & 2,77E-07 & intronic & CNBD1 \\
\hline rs74815096 & 8 & 128577675 & C & T & $-0,006$ & 0,006 & 0,242 & 0,063 & 0,014 & 0,192 & $-4,499$ & 6,79E-06 & intergenic & CASC8,CASC11 \\
\hline rs28687781 & 9 & 78496674 & G & A & 0,013 & 0,006 & 0,216 & $-0,061$ & 0,015 & 0,238 & 4,552 & 5,33E-06 & intergenic & MIR548H3,PCSK5 \\
\hline rs58733878 & 9 & 126968674 & C & G & $-0,005$ & 0,008 & 0,114 & 0,093 & 0,02 & 0,144 & $-4,542$ & 5,59E-06 & intergenic & LHX2,NEK6 \\
\hline rs112473634 & 9 & 136780781 & $\mathrm{~T}$ & C & $-0,007$ & 0,01 & 0,098 & 0,093 & 0,02 & 0,084 & $-4,428$ & $9,52 \mathrm{E}-06$ & intronic & VAV2 \\
\hline rs7095209 & 10 & 106781929 & A & G & 0,009 & 0,005 & 0,428 & $-0,064$ & 0,013 & 0,425 & 5,289 & $1,23 \mathrm{E}-07$ & intronic & SORCS3 \\
\hline rs55729345 & 10 & 115390091 & $\mathrm{C}$ & $\mathrm{T}$ & $-0,007$ & 0,005 & 0,367 & 0,057 & 0,013 & 0,407 & $-4,657$ & $3,18 \mathrm{E}-06$ & intronic & NRAP \\
\hline rs112017404 & 13 & 50165471 & $\mathrm{~T}$ & C & $-0,016$ & 0,01 & 0,061 & 0,12 & 0,024 & 0,085 & $-5,273$ & 1,35E-07 & intergenic & RCBTB1,ARL11 \\
\hline rs2819241 & 13 & 83709519 & C & $T$ & 0,026 & 0,008 & 0,152 & $-0,062$ & 0,016 & 0,123 & 4,837 & 1,33E-06 & intergenic & NONE,SLITRK1 \\
\hline rs2357001 & 14 & 64352814 & G & A & 0,014 & 0,005 & 0,663 & $-0,052$ & 0,012 & 0,625 & 4,96 & $7,01 \mathrm{E}-07$ & intronic & SYNE2 \\
\hline rs11851487 & 14 & 88284233 & A & $\mathrm{T}$ & $-0,021$ & 0,006 & 0,349 & 0,042 & 0,013 & 0,334 & $-4,447$ & 8,78E-06 & intergenic & LOC283585,GALC \\
\hline rs77506474 & 16 & 6068251 & G & A & $-0,009$ & 0,008 & 0,114 & 0,086 & 0,019 & 0,121 & $-4,504$ & 6,68E-06 & upstream & RBFOX1 \\
\hline rs74032742 & 16 & 78725080 & G & A & $-0,02$ & 0,009 & 0,076 & 0,096 & 0,023 & 0,085 & $-4,729$ & 2,26E-06 & intronic & wWOX \\
\hline rs11663276 & 18 & 8653957 & $\mathrm{~T}$ & $G$ & $-0,01$ & 0,008 & 0,136 & 0,083 & 0,017 & 0,144 & $-4,948$ & 7,53E-07 & intergenic & RAB12,GACAT2 \\
\hline rs60637140 & 18 & 13808717 & G & A & $-0,025$ & 0,01 & 0,072 & 0,097 & 0,025 & 0,073 & $-4,551$ & 5,36E-06 & intergenic & RNMT,MC5R \\
\hline rs67256262 & 19 & 1778023 & A & G & $-0,018$ & 0,006 & 0,201 & 0,059 & 0,015 & 0,237 & $-4,601$ & 4,20E-06 & intergenic & ONECUT3,ATP8B3 \\
\hline rs36010337 & 19 & 44530696 & C & A & $-0,021$ & 0,009 & 0,114 & 0,076 & 0,02 & 0,09 & $-4,43$ & $9,41 \mathrm{E}-06$ & intronic & ZNF222 \\
\hline rs113096000 & 20 & 35308843 & G & A & 0,012 & 0,006 & 0,258 & $-0,063$ & 0,014 & 0,27 & 4,87 & $1,12 \mathrm{E}-06$ & intronic & NDRG3 \\
\hline rs6025645 & 20 & 56157341 & A & G & 0,009 & 0,005 & 0,394 & $-0,054$ & 0,012 & 0,44 & 4,803 & $1,56 \mathrm{E}-06$ & intergenic & PCK1,ZBP1 \\
\hline rs9982779 & 21 & 20459913 & $\mathrm{~T}$ & G & $-0,008$ & 0,006 & 0,284 & 0,06 & 0,013 & 0,293 & $-4,727$ & $2,28 \mathrm{E}-06$ & intergenic & LOC101927797,LINC00320 \\
\hline rs9680265 & 21 & 22433521 & $\mathrm{~T}$ & C & $-0,007$ & 0,007 & 0,208 & 0,062 & 0,014 & 0,203 & $-4,418$ & 9,94E-06 & intronic & NCAM2 \\
\hline rs13058149 & 22 & 27831347 & $\mathrm{~T}$ & C & 0,006 & 0,005 & 0,515 & $-0,053$ & 0,012 & 0,473 & 4,51 & 6,49E-06 & intergenic & LINC01422,MN1 \\
\hline rs73425956 & 22 & 48984237 & A & G & $-0,007$ & 0,009 & 0,102 & 0,099 & 0,021 & 0,099 & $-4,623$ & 3,79E-06 & intronic & FAM19A5 \\
\hline
\end{tabular}

*Z_GXE shows Beta interaction. For beta interaction, positive values indicate association of allele A1 and increased CIMT; negative values indicate association of allele A1 with decreased cIMT.

${ }^{\Psi} \mathrm{A} 1$ is reflecting the alternative allele compared to the reference genome allele, all frequencies are reported for $A 1$. 
A
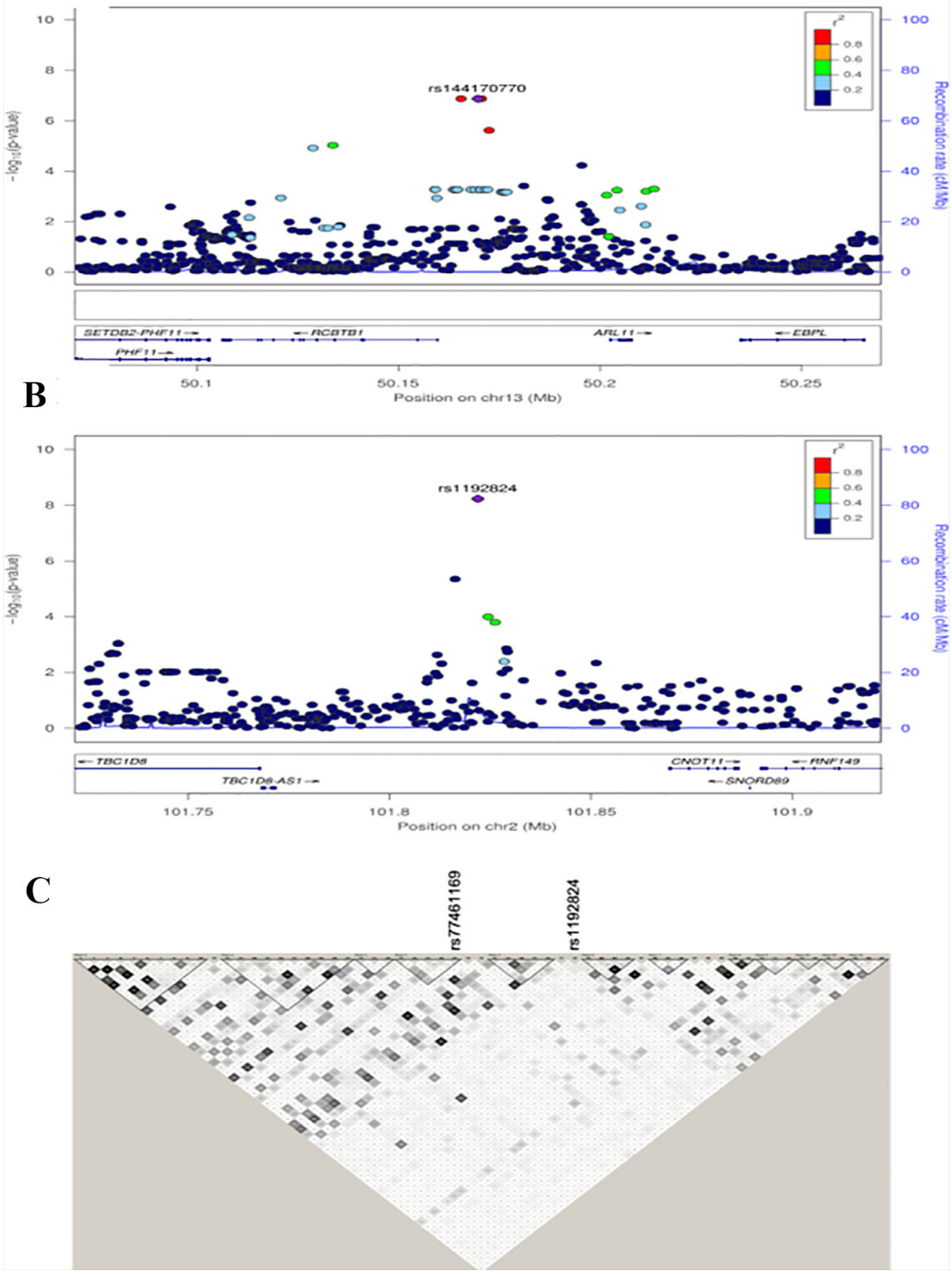

FIGURE 2 | Regional association plots for the RCBTB1 region in Nanoro (A). Regional association plots of TBC1D8 region in the combined data set (B). Distinct genomic risk loci were defined as linkage disequilibrium (LD)-independent regions $\left(r^{2}\right)$ separated by $100 \mathrm{~kb}$ and containing one or more SNPs with a suggestive association ( $p$-values $<1 \mathrm{E}-05$ ). For each locus, the plots show the -log10 transformed value of each SNP on the $y$-axis and base pair positions along the chromosomes on the x-axis. Genes overlapping the locus are displayed below the plot. SNPs are colored by their LD value with the lead SNP in the region, and those LD values were generated from the study populations. Haplotype blocks show that rs1192824 and rs77461169 are not in LD. Haplotype blocks were built using Haploview with LD values calculated from the two study populations together (C).

2017), lung cancer (McKay et al., 2017) and blood pressure (Taylor et al., 2016). Seventeen SNPs in the combined sample replicated previously reported interaction loci for gene-diabetes interaction for atherosclerotic plaque (Divers et al., 2017), gene-alcohol interaction for blood pressure (Feitosa et al., 2018), genesmoking interaction for BMI (Justice et al., 2017) and genesmoking interaction for blood pressure (Taylor et al., 2016; Sung et al., 2018). 


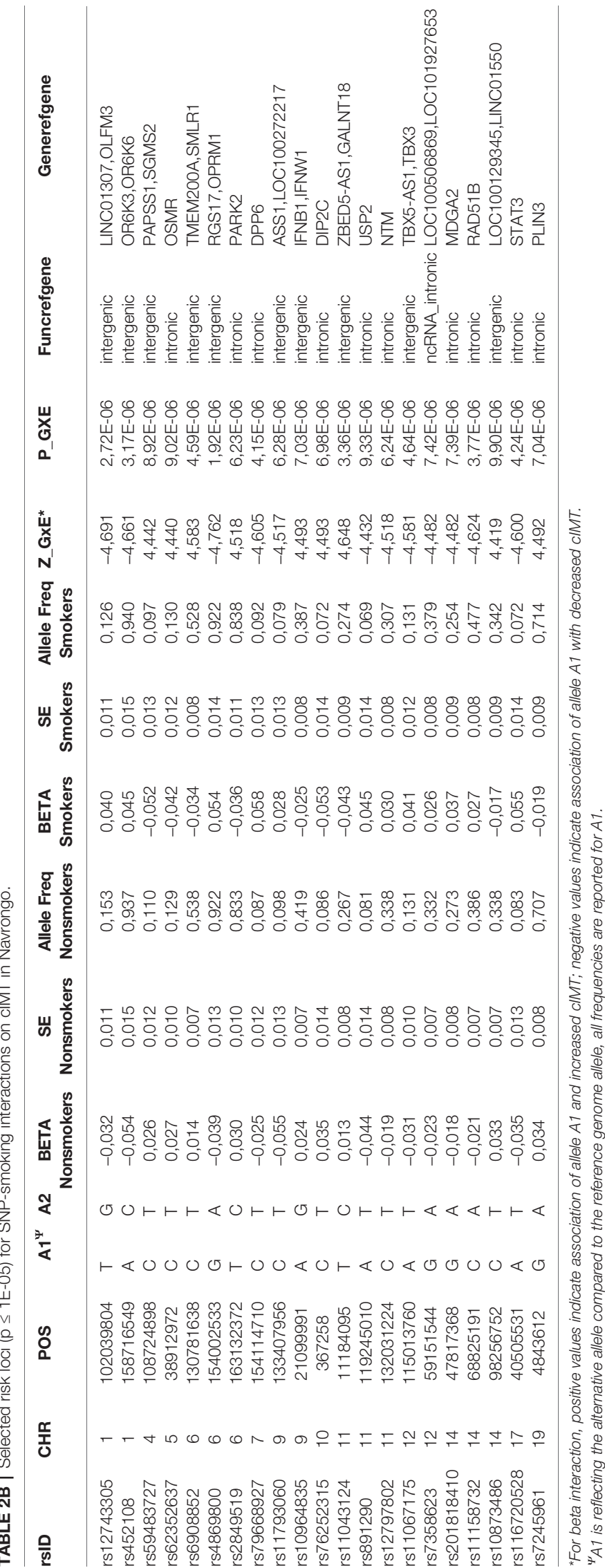

\section{Functional Analysis}

Functional annotation of SNPs with suggestive associations showed that these were mostly intronic or intergenic (Supplementary Tables 2A-C). 30 SNPs displayed a CADD score above 12.37 (17 in Nanoro; 3 in Navrongo; 10 in Combined), suspected to be deleterious. In the Nanoro sample, two SNPs (rs6701037, rs6677097), in high LD with rs10573305 (KIAA0040 region), had a RDB score of $1 \mathrm{f}$ suggesting they were likely affecting binding sites and gene expression. Equally, for the combined sample two variants (rs10409209 and rs4807840), in LD with rs8111212, displayed a RDB score of $1 \mathrm{f}$.

\section{Functional Annotation of Mapped Genes}

Genes implicated by mapping of significant SNPs were further investigated using the GENE2FUNC procedure in FUMA. Positional mapping, eQTL mapping (matched cis-eQTL SNPs) and chromatin interaction mapping (on the basis of 3D DNA-DNA interactions) are reported (Supplementary Tables 3A-C, Supplementary Figure 3). We found that rs1192824 and rs77461169 in TBC1D8 were implicated as eQTLs influencing the expression of TBC1D8, SNORD89, and RNF149 and also displaying chromatin interactions (Figure 4A). The RCBTB1 locus SNPs were eQTLs for RCBTB1, ARL11, CAB39L, and PSME2P2; their chromatin interactions included surrounding genes such as RCBTB1, KPNA3, CAB39L, SETDB2, MLNR, and CDADC1 (Figure 4B). A lookup into gene expression data sets, revealed expression of genes of interest in specific relevant tissues such as arteries (Supplementary Figure 4). We also analyzed the functional significance of the associated variants using FUN-LDA (Backenroth et al., 2018) and the results were largely similar to FUMA tissue-specific annotation.

\section{Gene Set Analysis}

Gene set analysis was only reported when at least five genes were implicated. In Nanoro, we found significant Gene Ontology Biological Processes for biological adhesion (AdjP $=2.69 \mathrm{E}-11)$, cell-cell adhesion $($ AdjP $=8.03 \mathrm{E}-11)$, homophilic cell adhesion via plasma membrane adhesion molecules (AdjP $=1.29 \mathrm{E}-09)$ and cell-cell adhesion via plasma membrane adhesion molecules (AdjP $=5.52 \mathrm{E}-09)$ (Figure 5; Supplementary Tables 4A-C).

\section{DISCUSSION}

Atherosclerosis is a low-grade chronic inflammatory condition characterized by aberrant lipid metabolism and a maladaptive inflammatory response. Biologically, the disease involves the formation of plaques in arterial walls and thickening that narrows the arterial passage, restricting blood flow and increasing the risk of occlusion resulting in a myocardial infarction and other events. Although environmental factors such as diet and/or smoking play an important role in the development of atherosclerosis, genetic factors represent 
TABLE 2C | Selected risk loci $(p \leq 1 E-05)$ for SNP-smoking interactions in combined sample.

\begin{tabular}{|c|c|c|c|c|c|c|c|c|c|c|c|c|c|c|}
\hline rsID & CHR & POS & $\mathrm{A} 1^{\Psi}$ & A2 & $\begin{array}{l}\text { BETA Non- } \\
\text { smokers }\end{array}$ & $\begin{array}{c}\text { SE } \\
\text { Nonsmokers }\end{array}$ & $\begin{array}{c}\text { Allele Freq } \\
\text { Nonsmokers }\end{array}$ & $\begin{array}{c}\text { BETA } \\
\text { Smokers }\end{array}$ & SE Smokers & $\begin{array}{l}\text { AlleleFreq } \\
\text { Smokers }\end{array}$ & Z_GxE $E^{\star}$ & P_GXE & Funcrefgene & Generefgene \\
\hline rs6685095 & 1 & 6502548 & T & C & $-0,005$ & 0,006 & 0,131 & 0,047 & 0,010 & 0,135 & $-4,519$ & 6,23E-06 & intronic & ESPN \\
\hline rs11588151 & 1 & 55487648 & G & A & $-0,024$ & 0,008 & 0,087 & 0,040 & 0,012 & 0,083 & $-4,518$ & $6,22 \mathrm{E}-06$ & intergenic & BSND,PCSK9 \\
\hline rs74115213 & 1 & 115054290 & G & $\mathrm{T}$ & $-0,012$ & 0,007 & 0,081 & 0,051 & 0,012 & 0,095 & $-4,439$ & $9,02 \mathrm{E}-06$ & upstream & TRIM33 \\
\hline rs1192824 & 2 & 101821934 & $\mathrm{~T}$ & C & 0,012 & 0,005 & 0,674 & $-0,039$ & 0,007 & 0,698 & 5,820 & 5,90E-09 & intergenic & TBC1D8,CNOT11 \\
\hline rs73047627 & 2 & 189842214 & A & G & 0,018 & 0,009 & 0,062 & $-0,057$ & 0,014 & 0,058 & 4,597 & 4,27E-06 & intronic & COL3A1 \\
\hline rs11695675 & 2 & 200607333 & A & G & $-0,022$ & 0,006 & 0,155 & 0,033 & 0,009 & 0,167 & $-5,095$ & 3,48E-07 & intergenic & LOC101927641,FTCDNL1 \\
\hline rs12465362 & 2 & 230587448 & T & $G$ & 0,010 & 0,005 & 0,226 & $-0,033$ & 0,008 & 0,238 & 4,475 & 7,63E-06 & intergenic & DNER,TRIP12 \\
\hline rs7619102 & 3 & 12728045 & A & G & 0,017 & 0,006 & 0,150 & $-0,034$ & 0,010 & 0,135 & 4,474 & $7,65 \mathrm{E}-06$ & intergenic & RAF1,TMEM40 \\
\hline rs869784 & 3 & 24348008 & C & $\mathrm{T}$ & 0,010 & 0,005 & 0,715 & $-0,029$ & 0,007 & 0,698 & 4,507 & 6,57E-06 & intronic & THRB \\
\hline rs9834968 & 3 & 69552204 & G & A & 0,019 & 0,008 & 0,086 & $-0,044$ & 0,012 & 0,082 & 4,481 & $7,45 E-06$ & intergenic & FRMD4B,MITF \\
\hline rs782444 & 3 & 127409941 & C & T & 0,009 & 0,004 & 0,473 & $-0,027$ & 0,007 & 0,473 & 4,596 & 4,32E-06 & UTR3 & MGLL \\
\hline rs76169119 & 4 & 40556609 & G & C & 0,022 & 0,009 & 0,063 & $-0,055$ & 0,014 & 0,058 & 4,658 & 3,20E-06 & intronic & RBM47 \\
\hline rs77655815 & 5 & 107952834 & A & $\mathrm{T}$ & $-0,016$ & 0,008 & 0,056 & 0,068 & 0,015 & 0,068 & $-4,882$ & 1,06E-06 & intergenic & FBXL17,LINC01023 \\
\hline rs10454990 & 5 & 148838117 & T & $\mathrm{C}$ & 0,025 & 0,006 & 0,138 & $-0,029$ & 0,010 & 0,129 & 4,558 & $5,17 \mathrm{E}-06$ & intergenic & MIR143HG,CSNK1A1 \\
\hline rs62435247 & 6 & 169725827 & G & A & 0,014 & 0,004 & 0,393 & $-0,024$ & 0,007 & 0,387 & 4,726 & 2,30E-06 & intergenic & THBS2,WDR27 \\
\hline rs62475193 & 7 & 154476372 & A & $G$ & $-0,009$ & 0,008 & 0,072 & 0,062 & 0,012 & 0,076 & $-4,792$ & $1,65 \mathrm{E}-06$ & intronic & DPP6 \\
\hline rs16900766 & 8 & 126649041 & G & A & $-0,006$ & 0,005 & 0,273 & 0,033 & 0,007 & 0,283 & $-4,458$ & 8,30E-06 & intergenic & TRIB1,LINC00861 \\
\hline rs74509340 & 10 & 480774 & C & $\mathrm{T}$ & 0,018 & 0,009 & 0,059 & $-0,065$ & 0,014 & 0,066 & 4,936 & 7,97E-07 & intronic & DIP2C \\
\hline rs1854462 & 10 & 91991941 & C & T & $-0,016$ & 0,007 & 0,102 & 0,042 & 0,011 & 0,103 & $-4,418$ & 9,95E-06 & intergenic & LINC01375,LOC101926942 \\
\hline rs112148169 & 10 & 133210477 & A & $\mathrm{T}$ & $-0,013$ & 0,008 & 0,075 & 0,057 & 0,013 & 0,076 & $-4,518$ & 6,26E-06 & intergenic & TCERG1L,LINC01164 \\
\hline rs1939309 & 11 & 100421331 & T & C & 0,011 & 0,005 & 0,731 & $-0,032$ & 0,008 & 0,740 & 4,681 & 2,84E-06 & intergenic & CNTN5,ARHGAP42 \\
\hline rs7492237 & 13 & 84258581 & T & $\mathrm{C}$ & 0,015 & 0,005 & 0,263 & $-0,029$ & 0,008 & 0,270 & 4,962 & 7,01E-07 & intergenic & NONE,SLITRK1 \\
\hline rs1546993 & 14 & 40153203 & A & G & 0,013 & 0,004 & 0,512 & $-0,026$ & 0,007 & 0,495 & 4,758 & 1,96E-06 & intergenic & FBXO33,LOC644919 \\
\hline rs60889063 & 16 & 54371831 & G & A & 0,011 & 0,005 & 0,233 & $-0,032$ & 0,008 & 0,235 & 4,593 & 4,39E-06 & intergenic & IRX3,CRNDE \\
\hline rs934166 & 16 & 84631300 & G & $A$ & $-0,005$ & 0,004 & 0,482 & 0,030 & 0,006 & 0,477 & $-4,581$ & 4,63E-06 & intronic & COTL1 \\
\hline rs11653290 & 17 & 6983529 & C & $A$ & $-0,019$ & 0,007 & 0,078 & 0,047 & 0,012 & 0,096 & $-4,599$ & 4,22E-06 & UTR5 & CLEC10A \\
\hline 17:21509395 & 17 & 21509395 & $\mathrm{~T}$ & C & $-0,015$ & 0,008 & 0,090 & 0,049 & 0,012 & 0,086 & $-4,537$ & 5,73E-06 & intergenic & C17orf51,FAM27L \\
\hline rs8067970 & 17 & 35145662 & A & G & 0,021 & 0,008 & 0,100 & $-0,042$ & 0,011 & 0,092 & 4,638 & 3,52E-06 & intergenic & MRM1,LHX1 \\
\hline rs10401037 & 17 & 52235347 & G & C & 0,007 & 0,005 & 0,261 & $-0,035$ & 0,008 & 0,223 & 4,625 & 3,76E-06 & intergenic & KIF2B,TOM1L1 \\
\hline rs4791039 & 17 & 64787600 & A & $G$ & $-0,013$ & 0,005 & 0,351 & 0,027 & 0,007 & 0,335 & $-4,764$ & 1,90E-06 & intronic & PRKCA \\
\hline rs551160836 & 18 & 41413084 & G & $\mathrm{T}$ & $-0,014$ & 0,009 & 0,078 & 0,058 & 0,012 & 0,069 & $-4,923$ & 8,49E-07 & intergenic & SYT4,LINC01478 \\
\hline rs8111212 & 19 & 6166665 & T & C & $-0,015$ & 0,004 & 0,602 & 0,022 & 0,007 & 0,600 & $-4,581$ & 4,65E-06 & intronic & ACSBG2 \\
\hline rs389332 & 21 & 18270964 & $G$ & C & $-0,018$ & 0,008 & 0,939 & 0,056 & 0,014 & 0,934 & $-4,425$ & 9,65E-06 & intergenic & MIR99AHG,LINC01549 \\
\hline rs9974620 & 21 & 36097794 & c & $T$ & $-0,006$ & 0,005 & 0,713 & 0,037 & 0,007 & 0,687 & $-4,922$ & 8,56E-07 & ncRNA_intronic & LINC00160 \\
\hline
\end{tabular}

*For beta interaction, positive values indicate association of allele A1 and increased CIMT; negative values indicate association of allele A1 with decreased cIMT.

${ }^{\top} \mathrm{A} 1$ is reflecting the alternative allele compared to the reference genome allele, all frequencies are reported for $A 1$. 

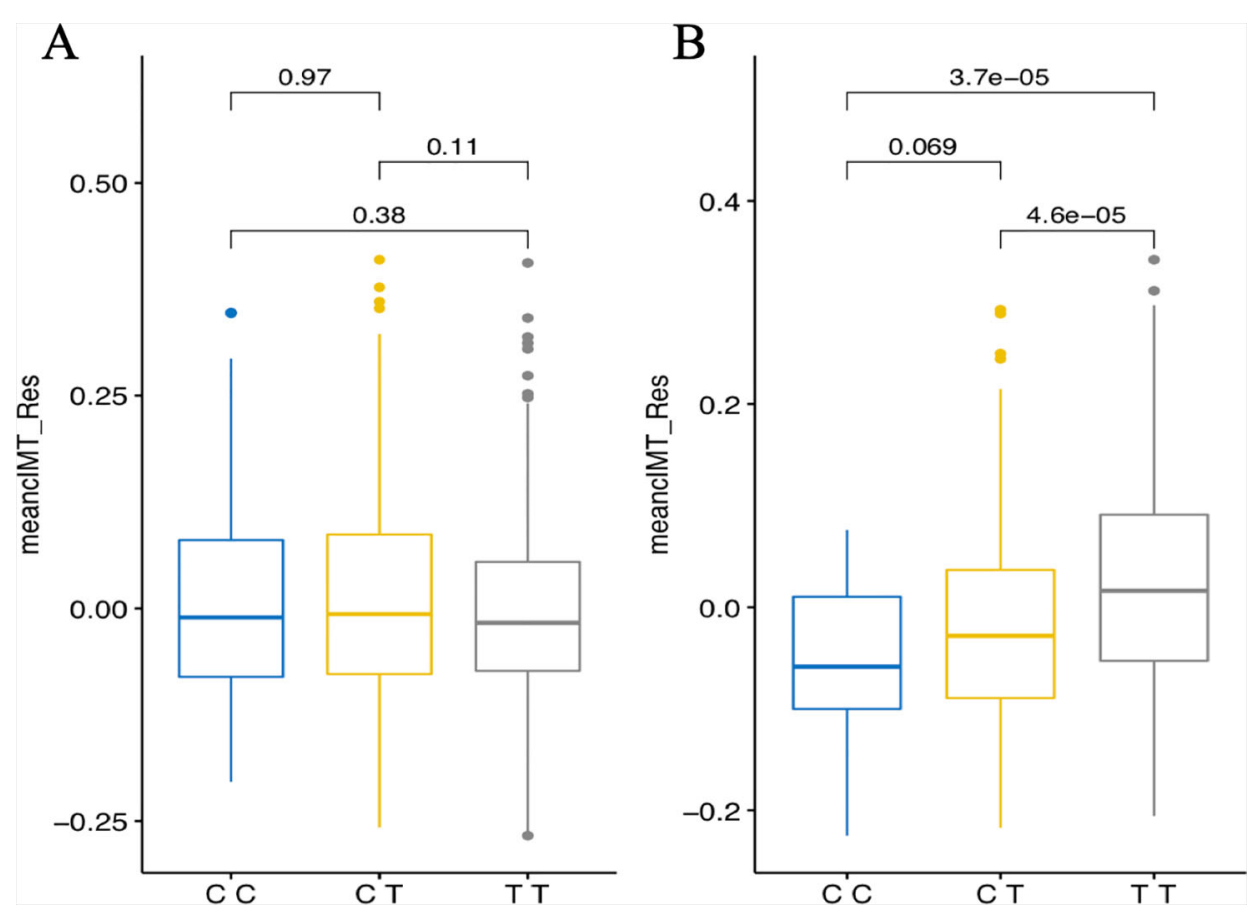

FIGURE 3 | Genotypes plots of rs1192824 in the combined set showing distributions of mean cIMT residuals [adjusted for age and six principal components (PCs) for population structure] in nonsmokers (A) and smokers (B). Mean_clMT_Res are in mm. Displayed p-values report comparisons between genotype groups performed using the Kruskal-Wallis test.

important determinants of atherosclerotic CVD risk. Key geneenvironment interactions may increase the risk for adverse outcomes by contributing to an increase of cIMT, and this was the aim of this study.

The gene-smoking interaction signals we identified for mean cIMT were with loci where the associated allele frequencies ranged from low to common, with most of them displaying effect sizes of over 4 . This suggests that the effects were unlikely to be attributed to additive independent effects of genetic-association and smoking, but rather to the interaction. The high effects provided us with sufficient power to discover the gene-smoking interactions, given our sample size. Moreover, many previously reported loci for $\mathrm{GxE}$ with cardiovascular-related traits were replicated, and our study identified new GxE variants for cIMT. The loci identified are biologically relevant in terms of the pathophysiology of atherosclerosis and involve genes implicated in macrophage activation and recruitment in the endothelial layer, cholesterol metabolism at the cellular level, inflammation processes and signalling, and cell membrane activity.

Our study is the first to report an association of TBC1D8 in the GxE interaction with cIMT and consequent risk for atherosclerosis. TBC1D8 (also called Vascular Rab-GAP/TBCcontaining protein) is a gene involved in blood circulation, intracellular protein transport and positive regulation of cell proliferation. The gene is regulated by vascular genes like VEGF, ACKR1, VEGFA, SIRT1, and TNF. Previous GWASs found variants in TBC1D8 associated with bone mass (Kiel et al., 2007), cognitive decline (Li et al., 2015) and osteoporosis
(Hsu et al., 2010) and found that TBC1D8 expression was subject to change under environmental stress. A study on the effect of smoking on gene expression found that TBC1D8 was differentially expressed in lymphocytes of smokers and nonsmokers (Charlesworth et al., 2010), as well as in macrophages from atherosclerotic plaques (Puig et al., 2011), depending on the inflammatory status of patients. Later Verdugo and colleagues (Verdugo et al., 2013) reported that TBC1D8 expression in monocytes was subject to a gene interaction with smoking among atherosclerotic patients, and that TBC1D8 was involved in one of the shortest gene paths between smoking and atherosclerotic plaques (smoking and plaques were separated by a relatively low number of genes). Their analysis of causality models provided evidence of gene expression partially mediating the relationship between smoking and atherosclerosis. Our study is therefore confirming the importance of TBC1D8 gene-environment interaction in atherosclerosis pathophysiology.

$R C B T B 1$, previously identified as a modifier for smoking on cIMT in multi-ethnic northern American populations, has been replicated in our study. The signal identified in our study is independent from the one previously described, although located in the same gene, the signal reported in the NOMAS study was led by the Hispanic population and located about $42 \mathrm{~kb}$ from our signal. But, the allele frequencies where highest in non-Hispanic blacks compared to Hispanic (rs3751383, MAF: 0.44 vs 0.25). Our data showed no LD $\left(\mathrm{r}^{2}<0.02\right)$ between the lead SNPs from the two studies (rs3751383, rs112017404). The RCBTB1 gene 
TABLE 3 | Comparison of gene-smoking association results for Nanoro and the combined sample (All), based on Model 1 and Model 2 for selected SNPs.

\begin{tabular}{|c|c|c|c|c|c|c|c|c|c|c|c|c|}
\hline \multirow[t]{2}{*}{ SNP } & \multirow[t]{2}{*}{ CHR } & \multirow[t]{2}{*}{ POS } & \multirow[t]{2}{*}{$\mathbf{A 1}$} & \multirow[t]{2}{*}{$\mathbf{A} 2$} & \multirow[t]{2}{*}{ All.P_GXE } & \multicolumn{4}{|c|}{ MODEL 1} & \multicolumn{3}{|c|}{ MODEL 2} \\
\hline & & & & & & $\begin{array}{c}\text { Beta } \\
\text { Interaction* }\end{array}$ & Nanoro.P_GXE & $\begin{array}{c}\text { Beta } \\
\text { Interaction* }\end{array}$ & All.P_GXE & $\begin{array}{c}\text { Beta } \\
\text { Interaction* }\end{array}$ & Nanoro.P_GXE & $\begin{array}{c}\text { Beta } \\
\text { Interaction* }\end{array}$ \\
\hline rs11161464 & 1 & 85298111 & $G$ & $A$ & 3,29E-03 & $-2,94$ & 7,34E-07 & $-4,95$ & 4,61E-03 & $-2,83$ & 2,14E-07 & $-5,19$ \\
\hline rs1192824 & 2 & 101821934 & $\mathbf{T}$ & C & $5,90 \mathrm{E}-09$ & 5,82 & $5,01 \mathrm{E}-04$ & 3,48 & $2,70 \mathrm{E}-08$ & 5,56 & $3,10 \mathrm{E}-03$ & 2,96 \\
\hline rs11695675 & 2 & 200607333 & $A$ & $G$ & $3,48 \mathrm{E}-07$ & $-5,10$ & $5,48 E-03$ & $-2,78$ & $3,27 \mathrm{E}-07$ & $-5,11$ & 9,66E-03 & $-2,59$ \\
\hline rs7649061 & 3 & 166457671 & A & C & 6,85E-04 & 3,40 & 7,37E-08 & 5,38 & 8,97E-04 & 3,32 & $2,20 E-08$ & 5,59 \\
\hline rs7615817 & 3 & 166528151 & $G$ & $A$ & $1,70 \mathrm{E}-04$ & 3,76 & $6,45 E-07$ & 4,98 & 2,01E-04 & 3,72 & 1,27E-06 & 4,84 \\
\hline rs2407218 & 5 & 121909381 & $\mathrm{G}$ & $A$ & 4,05E-02 & $-2,05$ & $5,78 \mathrm{E}-07$ & $-5,00$ & 3,20E-02 & $-2,14$ & 3,58E-07 & $-5,09$ \\
\hline 5:140208927 & 5 & 140208927 & $A$ & $\mathrm{C}$ & 7,98E-03 & $-2,65$ & 4,07E-07 & $-5,06$ & 1,08E-02 & $-2,55$ & $4,18 \mathrm{E}-07$ & $-5,06$ \\
\hline 5:140223827 & 5 & 140223827 & $A$ & $G$ & 1,15E-02 & $-2,53$ & $7,16 \mathrm{E}-07$ & $-4,96$ & 1,71E-02 & $-2,39$ & 1,23E-06 & $-4,85$ \\
\hline rs4728159 & 7 & 128856192 & $\mathrm{C}$ & $\mathrm{T}$ & 1,84E-02 & $-2,36$ & 6,07E-07 & $-4,99$ & 2,66E-02 & $-2,22$ & 4,96E-06 & $-4,57$ \\
\hline rs115650684 & 7 & 158660582 & $\mathrm{~T}$ & C & 7,74E-02 & $-1,77$ & 5,77E-07 & $-5,00$ & 1,49E-01 & $-1,44$ & 4,04E-06 & $-4,61$ \\
\hline rs6978311 & 7 & 158665920 & $A$ & $\mathrm{G}$ & 7,49E-02 & $-1,78$ & 5,47E-07 & $-5,01$ & 1,46E-01 & $-1,45$ & 3,93E-06 & $-4,61$ \\
\hline rs28890775 & 8 & 52207622 & $\mathrm{~T}$ & C & 9,83E-03 & $-2,58$ & 3,56E-07 & $-5,09$ & 8,92E-03 & $-2,62$ & 1,27E-06 & $-4,84$ \\
\hline rs13268575 & 8 & 88391237 & $\mathrm{C}$ & $A$ & 2,96E-02 & $-2,18$ & $2,77 \mathrm{E}-07$ & $-5,14$ & $4,14 \mathrm{E}-02$ & $-2,04$ & 1,54E-06 & $-4,81$ \\
\hline rs74509340 & 10 & 480774 & $\mathrm{C}$ & $\mathrm{T}$ & 7,97E-07 & 4,94 & 1,04E-01 & $-1,63$ & 2,05E-06 & 4,75 & 1,41E-01 & 1,47 \\
\hline rs7095209 & 10 & 106781929 & $A$ & $\mathrm{G}$ & 5,46E-02 & 1,92 & 1,23E-07 & $-5,29$ & 8,11E-02 & 1,74 & 1,90E-07 & 5,21 \\
\hline rs112017404 & 13 & 50165471 & $\mathbf{T}$ & C & 5,95E-03 & $-2,75$ & 1,35E-07 & $-5,27$ & 8,83E-03 & $-2,62$ & $3,08 E-08$ & $-5,54$ \\
\hline rs144170770 & 13 & 50169651 & $\mathbf{G}$ & A & 5,95E-03 & $-2,75$ & 1,35E-07 & $-5,27$ & 8,83E-03 & $-2,62$ & $3,08 E-08$ & $-5,54$ \\
\hline rs4941649 & 13 & 50170562 & C & A & 6,64E-03 & $-2,71$ & 1,35E-07 & $-5,27$ & 1,06E-02 & $-2,56$ & $3,08 E-08$ & $-5,54$ \\
\hline rs9546479 & 13 & 84256394 & C & $\mathrm{T}$ & 7,01E-07 & 4,96 & 1,45E-03 & 3,19 & 1,25E-06 & 4,85 & 1,10E-03 & 3,26 \\
\hline rs7492237 & 13 & 84258581 & $\mathrm{~T}$ & C & 7,01E-07 & 4,96 & 1,45E-03 & 3,19 & 1,25E-06 & 4,85 & 1,10E-03 & 3,26 \\
\hline rs12435958 & 14 & 64352150 & $\mathrm{C}$ & $\mathrm{G}$ & 5,93E-03 & 2,75 & 7,01E-07 & 4,96 & 2,46E-03 & 3,03 & 1,86E-06 & 4,77 \\
\hline rs2357001 & 14 & 64352814 & $G$ & A & 6,35E-03 & 2,73 & 7,01E-07 & 4,96 & 2,78E-03 & 2,99 & 1,86E-06 & 4,77 \\
\hline rs12895879 & 14 & 64353738 & $\mathrm{C}$ & $\mathrm{T}$ & 6,43E-03 & 2,72 & 7,19E-07 & 4,96 & 2,82E-03 & 2,99 & 1,90E-06 & 4,76 \\
\hline rs8004989 & 14 & 64354638 & $\mathrm{~T}$ & C & 6,08E-03 & 2,74 & 8,43E-07 & 4,92 & 2,65E-03 & 3,00 & $2,16 \mathrm{E}-06$ & 4,74 \\
\hline rs12444312 & 16 & 87097284 & $A$ & G & 2,95E-07 & $-5,13$ & 1,15E-03 & $-3,25$ & 1,46E-06 & $-4,82$ & 2,52E-03 & $-3,02$ \\
\hline rs11663276 & 18 & 8653957 & $\mathrm{~T}$ & G & 5,48E-02 & $-1,92$ & 7,53E-07 & $-4,95$ & 8,04E-02 & $-1,75$ & 1,46E-06 & $-4,82$ \\
\hline rs551160836 & 18 & 41413084 & $G$ & $\mathrm{~T}$ & 8,49E-07 & $-4,92$ & 3,96E-02 & $-2,06$ & $7,24 \mathrm{E}-07$ & $-4,96$ & 3,78E-02 & $-2,08$ \\
\hline rs9974620 & 21 & 36097794 & C & $\mathrm{T}$ & 8,56E-07 & $-4,92$ & 8,42E-04 & $-3,34$ & $6,48 \mathrm{E}-07$ & $-4,98$ & 6,67E-04 & $-3,40$ \\
\hline
\end{tabular}

${ }^{*}$ For beta interaction, positive values indicate smoking interaction with allele A1 results in increased cIMT; negative values indicate smoking interaction with allele A1 results in decreased clMT. In bold are the variants reaching genome-wide significance threshold $(p<5 E-08)$ in Model 2.

encodes a protein with an N-terminal RCC1 domain and a Cterminal BTB (broad complex, tramtrack, and bric-a-brac) domain. In rat, overexpression of this gene in vascular smooth muscle cells induced cellular hypertrophy. These results suggest that gene-smoking interaction for atherosclerosis might be acting through an intensification of monocyte activation and recruitment under the endothelial layers before their differentiation into macrophages, a process known to trigger foam cell formation and subsequent plaques (Jia et al., 2017). The results from the functional analyses suggest that the genesmoking interaction for cIMT is likely acting through a regulatory process, explaining the involvement of multiple loci displaying chromatin interactions and acting as eQTLs. We were able, in our study, to reproduce a GxE interaction for markers in $R C B T B 1$, albeit with an independent signal in the gene, demonstrating that the association is more generalizable. Our study is the first independent validation of the involvement of $R C B T B 1$ in gene-smoking interaction for cIMT.
There were differences in the association results between the two study sites with low replication. These differences may be partly explained by differences in the prevalence of smoking, sample sizes and smoking intensity. Effectively, the median smoking intensity in Nanoro was three times higher than in Navrongo (6.6 pack/year vs 1.7 pack/year) (Table 1), whereas the number of smokers in Nanoro $(n=132)$ was less than half of those in Navrongo $(n=333)$. A previous study using a systems biology approach revealed that cigarette smoke induced a concentration-dependent (direct and indirect) biological mechanism that promotes monocyte-endothelial cell adhesion (Poussin et al., 2015). Hence, the influence of smoking intensity on the detection of gene-smoking interaction was previously reported in a study of gene-smoking interaction for blood pressure in the Framingham Heart Study (Basson et al., 2015). They found different associated loci in the light smoker and the heavy smoker groups (>10 cigarettes per day). In the study by Wang et al. on gene-smoking interaction, the strongest association was among heavy smokers ( $\geq 20$ pack/year) 
A

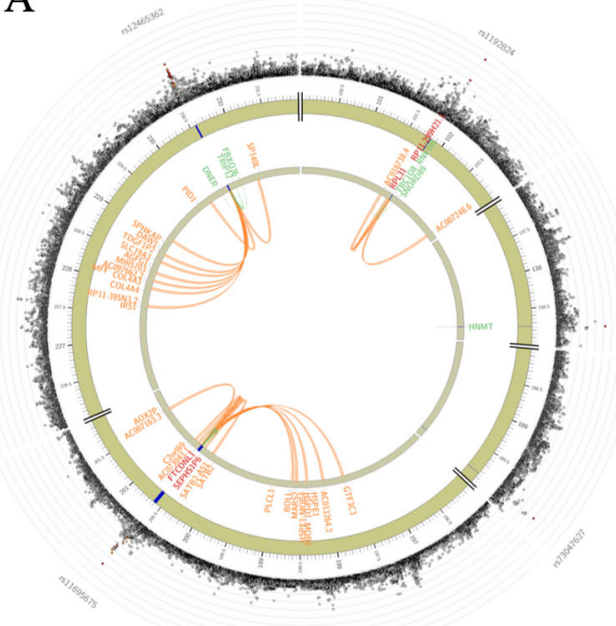

B

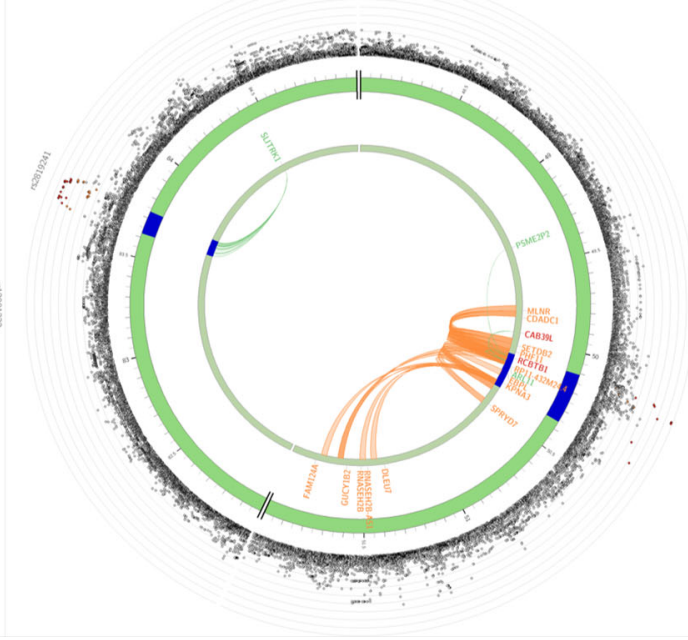

FIGURE 4 | Circos plots showing genes on chromosomes 2 for combined sample (A) and on chromosomes 13 for Nanoro sample (B). Blue regions are risk loci $(\mathrm{P}<1 \mathrm{E}-05)$. Green lines are connecting an eQTL SNP to its associated gene. Orange lines are connecting two interacting regions for chromatin interactions. Genes implicated by eQTLs are shown in green, by chromatin interactions are shown in orange, and by both eQTLs and chromatin interactions are shown in red. The outer layer shows a Manhattan plot containing the - $\log ^{10}$-transformed two-tailed p-value of each SNP from the gene-environment interaction analysis, with SNPs colored according to LD patterns with the lead SNP. Higher-resolution Circos plots for all chromosomes are provided in Supplementary Figure $\mathbf{3}$.

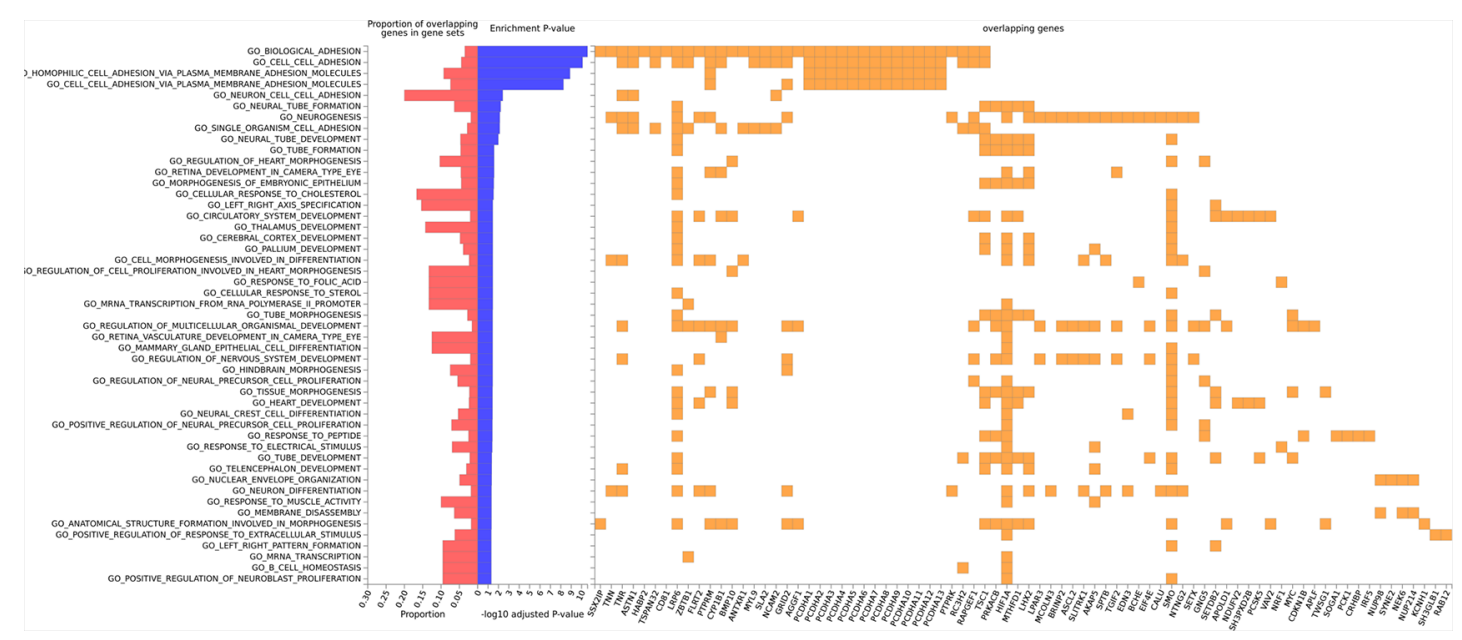

FIGURE 5 | Gene ontology enrichment for biological processes for gene-smoking interaction on cIMT in Nanoro, with overlapping genes in gene sets.

(Wang et al., 2014). This might explain why the RCBTB1 region was only replicated in Nanoro, where the smoking intensity was higher than in Navrongo.

We report a substantial number of suggestive GxE signals that may be African-specific as they have not yet been observed in non-African studies with larger cohorts. Since African genetic diversity is generally higher, it is possible that there are more novel gene variants that are related to pathways involved in complex diseases like atherosclerosis (Sulovari et al., 2017). Our study is restricted to men and is limited by the sample size and relatively low prevalence of smokers in Nanoro. There was, however, sufficient power to detect the effect sizes we observed, and our sample size exceeded several previously published studies. In the design of the study, an inclusion criterion was that participants should not be closely related (Ali et al., 2018); however the genetic data revealed several individuals with first and second degree relatedness (204 in nonsmokers, 62 in smokers; $15 \%)$. To mitigate the effect of relatedness, we ran the 
analysis using GEMMA, a program that adjusts using the kinship matrix (Zhou et al., 2012). The comparison of the results from GEMMA (gxe option) and from PLINK (gxe option) showed that the outputs were highly correlated, indicating that relatedness had little effect on the outcomes.

Probable contributors to the heterogeneity of signals between the two geographical groups include differences in the patterns of smoking exposure and the simplistic measure of smoking status that we used in this study (current smokers vs nonsmokers), over the use of a continuous measure (pack/year).

\section{CONCLUSION}

Our study provides the first report of gene-smoking interactions for cIMT in sub-Saharan African populations. We identified novel genome-wide significant variants in TBC1D8 for interactions with smoking for cIMT. The replication of eight previous signals identified in non-African populations, demonstrates that these signals are transferable to West Africa. The discovery of the novel signals, on the other hand, indicates the possibility of African-specific associations. The strategies of functional annotation and gene mapping using biological data resources provided useful information on the likely consequences of relevant genetic variants and identified plausible gene targets and biological mechanisms for functional follow-up. Gene set analyses contributed novel insight into underlying pathways, confirming the importance of geneenvironment interactions in atherosclerosis and pointing toward the involvement of specific cell types. Gene-environment GWASs will benefit from colocalization analyses for interpreting the biological and clinical relevance of the GWAS results. When variants associated with $\mathrm{GxE}$ are present at high frequency in target populations, this provides an opportunity for precision public health. Future studies based on populations from other African regions may provide validation of transferability to SSA more generally, identify further novel signals and to generate more insights into the relationship between these associations disease pathophysiology.

\section{DATA AVAILABILITY STATEMENT}

The raw data supporting the conclusions of this manuscript will be made available by the authors, without undue reservation, to any qualified researcher.

\section{ETHICS STATEMENT}

This study received the approval of the Human Research Ethics Committee (Medical), University of the Witwatersrand/South Africa (M121029), the approval of the Centre Muraz Institutional Ethics Committee/Burkina Faso (015-2014/CE$\mathrm{CM}$ ) and the approval of the National Ethics Committee For Health Research/Burkina Faso (2014-08-096), the Ghana Health Service Ethics Review Committee (ID No: GHS-ERC:05/05/
2015) and the Navrongo Institutional Review Board (ID No: NHRCIRB178). All the participants signed an Informed Consent Form before any study procedure was performed.

\section{AUTHOR CONTRIBUTIONS}

PB, HS, HT, AC, CM, and MR designed the study. PB and J-TB performed the analysis. DS performed the imputation. $\mathrm{PB}$ wrote the manuscript. PB, J-TB, AC, CM, HS, DS, SH, GA, EN, AO, HT and $\mathrm{MR}$ critically reviewed and approved the manuscript.

\section{FUNDING}

This study was funded by the National Institutes of Health (NIH) through the H3Africa AWI-Gen project (NIH grant number U54HG006938) and the Wits Non-Communicable Disease Research Leadership Programme (NIH Fogarty International Centre grant number D43TW008330). AWI-Gen is supported by the National Human Genome Research Institute (NHGRI), Eunice Kennedy Shriver National Institute of Child Health \& Human Development (NICHD), Office of the Director (OD) at the National Institutes of Health. PB is funded by the National Research Fondation/The World Academy of Sciences "African Renaissance Doctoral Fellowship” (Grant no. 100004).

\section{ACKNOWLEDGMENTS}

This study would not have been possible without the generosity of the participants who spent many hours responding to questionnaires, being measured and having samples taken. We wish to acknowledge the sterling contributions of our field workers, phlebotomists, laboratory scientists, administrators, data personnel, and all other staff who contributed to the data and sample collections, processing, storage, and shipping. Investigators responsible for the conception and design of the AWI-Gen study include the following: MR (PI, Wits), Osman Sankoh (co-PI, INDEPTH), Stephen Tollman, and Kathleen Kahn (Agincourt PI), Marianne Alberts (Dikgale PI), Catherine Kyobutungi (Nairobi PI), HT (Nanoro PI), AO (Navrongo PI), Shane Norris (Soweto PI), and SH, Nigel Crowther, Himla Soodyall, and Zane Lombard (Wits).We would like to acknowledge each of the following investigators for their significant contributions to this research, mentioned according to affiliation: Wits AWI-Gen Collaborative Centre: Stuart Ali, AC, SH, Freedom Mukomana, Cassandra Soo; Soweto (DPHRU): Nomses Baloyi, Yusuf Guman.

\section{SUPPLEMENTARY MATERIAL}

The Supplementary Material for this article can be found online at: https://www.frontiersin.org/articles/10.3389/fgene.2019. 01354/full\#supplementary-material 


\section{REFERENCES}

Ali, S. A., Soo, C., Agongo, G., Alberts, M., Amenga-Etego, L., Boua, R. P., et al. (2018). Genomic and environmental risk factors for cardiometabolic diseases in Africa: methods used for phase 1 of the AWI-Gen population cross-sectional study. Global Health Action 11 (sup2), 4-21. doi: 10.1080/ 16549716.2018.1507133

Backenroth, D., He, Z., Kiryluk, K., Boeva, V., Pethukova, L., Khurana, E., et al. (2018). FUN-LDA: a latent dirichlet allocation model for predicting tissue-specific functional effects of noncoding variation: methods and applications. Am. J. Hum. Genet. 102 (5), 920-942. doi: 10.1016/ j.ajhg.2018.03.026

Baichoo, S., Souilmi, Y., Panji, S., Botha, G., Meintjes, A., Hazelhurst, S., et al. (2018). Developing reproducible bioinformatics analysis workflows for heterogeneous computing environments to support African genomics. $B M C$ Bioinf. 19 (1), 457. doi: 10.1186/s12859-018-2446-1

Barua, R. S., and Ambrose, J. A. (2013). Mechanisms of coronary thrombosis in cigarette smoke exposure. Arteriosclerosis Thrombosis Vasc. Biol. 33 (7), 14601467. doi: 10.1161/ATVBAHA.112.300154

Basson, J., Sung, Y. J., de las Fuentes, L., Schwander, K., Cupples, L. A., and Rao, D. C. (2015). Influence of smoking status and intensity on discovery of blood pressure loci through gene-smoking interactions. Genet. Epidemiol. 39 (6), 480-488. doi: 10.1002/gepi.21904

Boyle, A. P., Hong, E. L., Hariharan, M., Cheng, Y., Marc, A., Kasowski, S. M., et al. (2012). Annotation of functional variation in personal genomes using regulomeDB. Genome Res. 22 (9), 1790-1797. doi: 10.1101/gr.137323.112

Chang, C. C., Chow, C. C., Tellier, L. C., Vattikuti, S., Purcell, S. M., and Lee, J. J. (2015). Second-generation PLINK: rising to the challenge of larger and richer datasets. GigaScience 4 (1), 7. doi: 10.1186/s13742-015-0047-8

Charlesworth, J. C., Curran, J. E., Johnson, M. P., Göring, H. H. H., Dyer, T. D., Diego, V. P., et al. (2010). Transcriptomic epidemiology of smoking: the effect of smoking on gene expression in lymphocytes. BMC Med. Genomics 3 (1), 29. doi: 10.1186/1755-8794-3-29

Chen, X. S., Reader, R. H., Hoischen, A., Veltman, J. A., Nuala, H., Francks, S. C., et al. (2017). Next-generation DNA sequencing identifies novel gene variants and pathways involved in specific language impairment. Sci. Rep. 7, 1-17. doi: $10.1038 /$ srep46105

Choudhury, A., Aron, S., Sengupta, D., and Hazelhurst, S. (2018). African genetic diversity provides novel insights into evolutionary history and local adaptations. Hum. Mol. Genet. 0 (0), 1-10. doi: 10.1093/hmg/ddy161

Consortium Roadmap Epigenomics, Kundaje, A., Meuleman, W., Ernst, J., Bilenky, M., Yen, A., et al. (2015). Integrative analysis of 111 reference human epigenomes. Nature 518 (7539), 317-330. doi: 10.1038/nature14248

Della-Morte, D., Wang, L., Beecham, A., Susan, H., Zhao, B. H., Ralph, L., et al. (2014). Novel genetic variants modify the effect of smoking on carotid plaque burden in Hispanics. J. Neurological Sci. 344 (1-2), 27-31. doi: 10.1016/ j.jns.2014.06.006

Derra, K., Rouamba, E., Kazienga, A., Ouedraogo, S., Tahita, M. C., Sorgho, H., et al. (2012). Profile: Nanoro health and demographic surveillance system. Int. J. Epidemiol. 41 (5), 1293-1301. doi: 10.1093/ije/dys159

Divers, J., Palmer, N. D., Langefeld, C. D., Brown, W. M., Lu, L., Hicks, P. J., et al. (2017). Genome-wide association study of coronary artery calcified atherosclerotic plaque in African americans with type 2 diabetes. $B M C$ Genet. 18 (1), 1-13. doi: 10.1186/s12863-017-0572-9

Duncan, E., Brown, M., Shore, E. M., Sainani, K., MacArthur, D., Balasubramanian, S., et al. (2014). Unlocking the genetics of complex diseases: the GWAS and beyond. Bioinformatics 5, 1-14. doi: 10.3389/ fgene.2014.00250

Ernst, J., and Kellis, M. (2013). ChromHMM: automating chromatin state discovery and characterization supplementary material. Nat. Methods 9 (3), 215-216. doi: 10.1038/nmeth.1906

Feitosa, M. F., Kraja, A. T., Chasman, D. I., Sung, Y. J., Winkler, T. W., Ntalla, I., et al. (2018). Novel genetic associations for blood pressure identified via genealcohol interaction in up to 570k individuals across multiple ancestries. PloS One 13 (6), 1-36. doi: 10.1371/journal.pone.0198166

GTex Consortium, Aguet, F., Brown, A. A., Castel, S. E., Davis, J. R., He, Y., et al. (2017). Genetic effects on gene expression across human tissues. Nature 550 (7675), 204-213. doi: 10.1038/nature24277
Hansen, K., Östling, G., Persson, M., Nilsson, P. M., Melander, O., Engström, G., et al. (2016). European journal of internal medicine the effect of smoking on carotid intima - media thickness progression rate and rate of lumen diameter reduction. Eur. J. Internal Med. 28, 74-79. doi: 10.1016/j.ejim.2015.10.018

Hsu, Y. H., Zillikens, M. C., Wilson, S. G., Farber, C. R., Demissie, S., Soranzo, N., et al. (2010). An integration of genome-wide association study and gene expression profiling to prioritize the discovery of novel susceptibility loci for osteoporosis-related traits. PloS Genet. 6 (6), 1-16. doi: 10.1371/ journal.pgen.1000977

Jia, S. J., Gao, K. Q., and Zhao, M. (2017). Epigenetic regulation in monocyte/ macrophage: a key player during atherosclerosis. Cardiovasc. Ther. 35 (3), 1 11. doi: $10.1111 / 1755-5922.12262$

Justice, A. E., Winkler, T. W., Feitosa, M. F., Graff, M., Fisher, V. A., Young, K., et al. (2017). Genome-wide meta-analysis of 241,258 adults accounting for smoking behaviour identifies novel loci for obesity traits. Nat. Commun. 8, 119. doi: $10.1038 /$ ncomms 14977

Kianoush, S., Yakoob, M. Y., Al-Rifai, M., DeFilippis, A. P., Bittencourt, M. S., Duncan, B. B., et al. (2017). Associations of cigarette smoking with subclinical inflammation and atherosclerosis: ELSA-Brasil (the brazilian longitudinal study of adult health). J. Am. Heart Assoc. 6 (6), e005088. doi: 10.1161/ JAHA.116.005088

Kiel, P. D., Demissie, S., Dupuis, J., Lunetta, K. L., Murabito, J. M., and Karasik, D. (2007). Genome-wide association with bone mass and geometry in the Framingham heart study. BMC Med. Genet. 4 (8), 1-13. doi: 10.1186/14712350-8-S1-S14

Kircher, M., Witten, D. M., Jain, P., O'roak, B. J., Cooper, G. M., and Shendure, J. (2014). A general framework for estimating the relative pathogenicity of human genetic variants. Nat. Genet. 46 (3), 310-315. doi: 10.1038/ng.2892

Li, C., Chen, W., Jiang, F., Simino, J., Srinivasan, S. R., Berenson, G. S., et al. (2015). Genetic association and gene-smoking interaction study of carotid intimamedia thickness at five GWAS-indicated genes: the Bogalusa Heart Study. Gene 562 (2), 226-231. doi: 10.1016/j.gene.2015.02.078

Liang, L. R., Wong, N. D., Shi, P., Zhao, L. C., Wu, L. X., Xie, G. Q., et al. (2009). Cross-sectional and longitudinal association of cigarette smoking with carotid atherosclerosis in Chinese adults. Preventive Med. 49 (1), 62-67. doi: 10.1016/ j.ypmed.2009.05.006

Loh, P. R., Danecek, P., Palamara, P. F., Fuchsberger, C., Reshef, Y. A., Finucane, H. K., et al. (2016). Reference-based phasing using the haplotype reference consortium panel. Nat. Genet. 48 (11), 1443-1448. doi: 10.1038/ ng. 3679

Martin, A. R., Teferra, S., Mo, M., Hoal, E. G., and Daly, M. J. (2018). The critical needs and challenges for genetic architecture studies in Africa. Curr. Opin. Genet. Dev. 53, 113-120. doi: 10.1016/j.gde.2018.08.005

McKay, J D., Hung, R. J., Han, Y., Zong, X., Carreras-Torres, R., David Christiani, C., et al. (2017). Large-scale association analysis identifies new lung cancer susceptibility loci and heterogeneity in genetic susceptibility across histological subtypes. Nat. Genet. 49 (7), 1126-1132. doi: 10.1038/ng.3892

Oduro, A. R., Wak, G., Azongo, D., Debpuur, C., Wontuo, P., Kondayire, F., et al. (2012). Profile of the Navrongo health and demographic surveillance system. Int. J. Epidemiol. 41 (4), 968-976. doi: 10.1093/ije/dys111

Park, S. L., Carmella, S. G., Chen, M., and Patel, Y. (2015). Mercapturic acids derived from the toxicants acrolein and crotonaldehyde in the urine of cigarette smokers from five ethnic groups with differing risks for. PloS One 10 (6), 1-17. doi: 10.1371/journal.pone.0124841

Polfus, L. M., Smith, J. A., Shimmin, L. C., Bielak, L. F., Morrison, A. C., Kardia, S. L. R., et al. (2013). Genome-wide association study of gene by smoking interactions in coronary artery calcification. PloS One 8, 10. doi: 10.1371/journal.pone. 0074642

Popejoy, A. B., and Fullerton, S. M. (2016). Supplementary information to: genomics is failing on diversity comment in nature. Nature 538, 161-164. doi: $10.1038 / 538161$ a

Poussin, C., Laurent, A., Peitsch, M. C., Hoeng, J., De Leon, H., P Morris International, R., et al. (2015). Systems biology reveals cigarette smokeinduced concentration-dependent direct and indirect mechanisms that promote monocyte - endothelial cell adhesion. Toxicol. Sci. 147, 2, 370-385. doi: $10.1093 /$ toxsci/kfv137

Puig, O., Yuan, J., Stepaniants, S., Zieba, R., Zycband, E., Morris, M., et al. (2011). A gene expression signature that classifies human atherosclerotic plaque by 
relative inflammation status. Circ. Cardiovasc. Genet. 4 (6), 595-604. doi: 10.1161/CIRCGENETICS.111.960773

Purcell, S., Neale, B., Todd-Brown, K., Thomas, L., Ferreira, M. A. R., Bender, D., et al. (2007). PLINK: a tool set for whole-genome association and populationbased linkage analyses. Am. J. Hum. Genet. 81 (3), 559-575. doi: 10.1086/ 519795

Ramsay, M., Crowther, N., Tambo, E., Agongo, G., Baloyi, V., Dikotope, S., et al. (2016). H3Africa AWI-Gen collaborative centre: a resource to study the interplay between genomic and environmental risk factors for cardiometabolic diseases in four sub-Saharan African countries. Global Health Epidemiol. Genomics 1, e20. doi: 10.1017/gheg.2016.17

Roth, G. A., Huffman, M. D., Moran, A. E., Feigin, V., Mensah, G. A., Naghavi, M., et al. (2015). Global and regional patterns in cardiovascular mortality from 1990 to 2013. Circulation 132 (17), 1667-1678. doi: $10.1161 /$ CIRCULATIONAHA.114.008720

Saleheen, D., Zhao, W., Young, R., Nelson, C. P., Ho, W., Ferguson, J. F., et al. (2017). Loss of cardioprotective effects at the ADAMTS7 locus as a result of gene-smoking interactions. Circulation 135 (24), 2336-2353. doi: 10.1161/ CIRCULATIONAHA.116.022069

Schroeder, S. A. (2013). New evidence that cigarette smoking remains the the most important health hazard. New Engl. J. Med. 368 (4), 389-390. doi: 10.1056/ NEJMe1215043

Sulovari, A., Chen, Y. H., Hudziak, J. J., and Li, D. (2017). Atlas of human diseases influenced by genetic variants with extreme allele frequency differences. Hum. Genet. 136 (1), 39-54. doi: 10.1007/s00439-016-1734-y

Sung, Y. J., Winkler, T. W., de las Fuentes, L., Bentley, A. R., Brown, M. R., Kraja, A. T., et al. (2018). A large-scale multi-ancestry genome-wide study accounting for smoking behavior identifies multiple significant loci for blood pressure. Am. J. Hum. Genet. 102 (3), 375-400. doi: 10.1016/j.ajhg.2018.01.015

Taylor, J. Y., Schwander, K., Kardia, S. L. R., Arnett, D., Liang, J., Hunt, S. C., et al. (2016). A genome-wide study of blood pressure in African Americans accounting for gene-smoking interaction. Sci. Rep. 6, 18812. doi: 10.1038/ srep 18812

Tekola-Ayele, I. F., and Rotimi, N. C. (2015). Translational genomics in low- and middle-income countries: opportunities and challenges. Public Health Genom., 18, 242-247. doi: 10.1159/000433518

The GTExArd Consortium, Welter, D., MacArthur, J., Morales, J., Burdett, T., Hall, P., et al. (2015). The Genotype-Tissue Expression (GTEx) pilot analysis: multitissue gene regulation in humans. Science 348 (6235), 648-660. doi: $10.1126 /$ science. 1262110

Verdugo, R. A., Zeller, T., Rotival, M., Philipp, S., Münzel, W. T., Lackner, K. J., et al. (2013). Graphical modeling of gene expression in monocytes suggests molecular mechanisms explaining increased atherosclerosis in smokers. PloS One 8, 1. doi: 10.1371/journal.pone.0050888

Wang, K., Li, M., and Hakonarson, H. (2010). ANNOVAR: functional annotation of genetic variants from high-throughput sequencing data. Nucleic Acid Res. 38, 16, 1-7. doi: 10.1093/nar/gkq603

Wang, L., Rundek, T., Beecham, A., Hudson, B., Blanton, S. H., Zhao, H., et al. (2014). Genome-wide interaction study identifies RCBTB1 as a modifier for smoking effect on carotid intima-media thickness. Arteriosclerosis Thrombosis Vasc. Biol. 34 (1), 219-225. doi: 10.1161/ATVBAHA.113.302706

Ward-Caviness, Cavin, K., Neas, L. M., Blach, C., Haynes, Carol S., LarocqueAbramson, K., et al. (2017). A genome-wide trans-ethnic interaction study links the PIGR-FCAMR locus to coronary atherosclerosis via interactions between genetic variants and residential exposure to traffic. PloS One 12 (3), 116. doi: 10.1371 /journal.pone. 0173880

Watanabe, K., Taskesen, E., van Bochoven, A., and Posthuma, D. (2017), Functional mapping and annotation of genetic associations with FUMA. Nat. Communications 8, 1-10. doi: 10.1038/s41467-017-01261-5

Yang, D., Iyer, S., Gardener, H., Della-Morte, D., Crisby, M., Dong, C., et al. (2015). Cigarette smoking and carotid plaque echodensity in the Northern Manhattan study. Cerebrovascular Dis. 40 (3-4), 136-143. doi: 10.1159/000434761

Zhou, X., and Stephens, M. (2012). Genome-wide efficient mixed model analysis for association studies. Nature Genet. 44 (7), 821-824. doi: 10.1038/ng.2310

Conflict of Interest: The authors declare that the research was conducted in the absence of any commercial or financial relationships that could be construed as a potential conflict of interest.

Copyright (c) 2020 Boua, Brandenburg, Choudhury, Hazelhurst, Sengupta, Agongo, Nonterah, Oduro, Tinto, Mathew, Sorgho and Ramsay. This is an open-access article distributed under the terms of the Creative Commons Attribution License (CC BY). The use, distribution or reproduction in other forums is permitted, provided the original author(s) and the copyright owner(s) are credited and that the original publication in this journal is cited, in accordance with accepted academic practice. No use, distribution or reproduction is permitted which does not comply with these terms. 